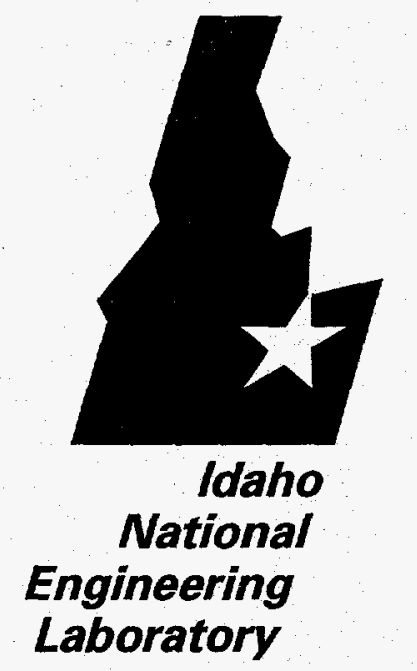

Engineering

Laboratory
INEL-95/0321

July 1995

\section{AECEIVED \\ OCT 201995 \\ OSTI}

Buried Waste Integrated Demonstration Fiscal Year 1994 Close-Out Report

Katherine J. Owen

\section{MASTER}

亏2Lockheed

Idaho Technologles Company 


\section{DISCLAIMER}

This report was prepared as an account of work sponsored by an agency of the United States Government. Neither the United States Government nor any agency thereot, nor any of their employees, makes any warranty, express or implied, or assumes any legal liability or responsibility for the accuracy, completeness, or usefulness of any information, apparatus, product or process disclosed, or represents that its use would not infringe privately owned rights. References herein to any specific commercial product, process, or service by trade name, trademark, manufacturer, or othenwise, does not necessarily constitute or imply its endorsement, recommendation, or favoring by the United States Government or any agency thereof. The views and opinions of authors expressed herein do not necessarily state or reflect those of the United States Government or any agency thereot. 


\section{DISCLAIMER}

Portions of this document may be illegible in electronic image products. Images are produced from the best available original document. 


\title{
Buried Waste Integrated Demonstration Fiscal Year 1994 Close-Out Report
}

\author{
Katherine J. Owens
}

Published July 1995

\section{Idaho National Engineering Laboratory Lockheed Idaho Technologies Company Idaho Falls, Idaho 83415}

Prepared for the

U.S. Department of Energy

Office of Environmental Restoration and Waste Management Under DOE Idaho Operations Office Contract DE-AC07-94ID13223

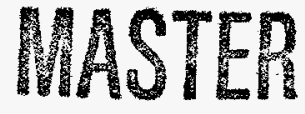




\section{Buried Waste Integrated Demonstration Fiscal Year 1994 Close-Out Report}

INEL-95/0321

Prepared by
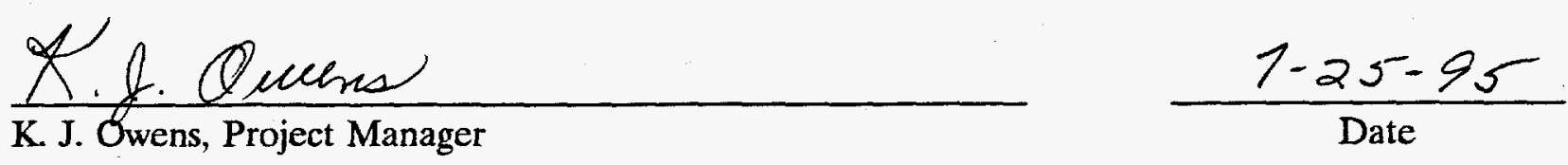

Reviewed by

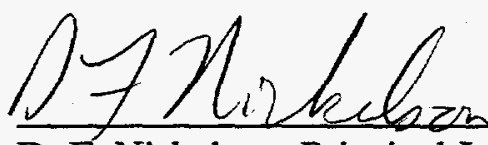

D. F. Nickelson, Principal Investigator

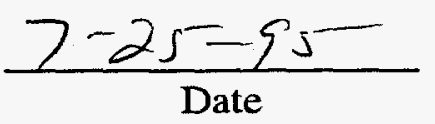

Approved by

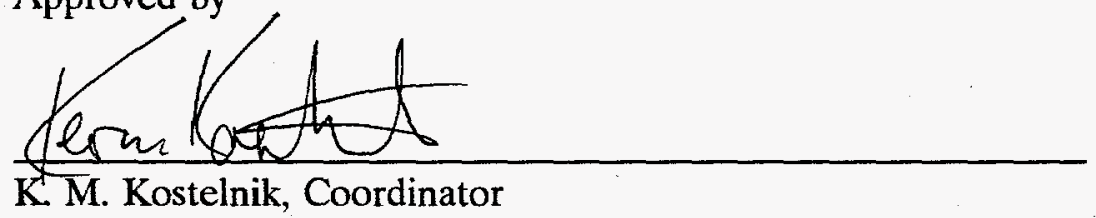

K. M. Kostelnik, Coordinator

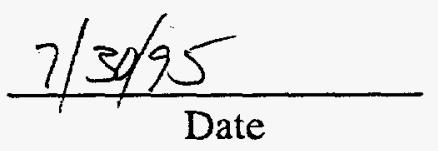

Buried Waste Integrated Demonstration 



\begin{abstract}
The Buried Waste Integrated Demonstration (BWID) supports the applied research, development, demonstration, and evaluation of a multitude of advanced technologies. These technologies are being integrated to form a comprehensive remediation system for the effective and efficient remediation of buried waste. These efforts are identified and coordinated in support of the U.S. Department of Energy Environmental Restoration and Waste Management needs and objectives. BWID works with universities and private industry to develop these technologies, which are being transferred to the private sector for use nationally and internationally. A public participation policy has been established to provide stakeholders with timely and accurate information and meaningful opportunities for involvement in the technology development and demonstration process. To accomplish this mission of identifying technological solutions for remediation deficiencies, the Department of Energy Office of Technology Development initiated BWID at the Idaho National Engineering Laboratory. This report summarizes the activities of the BWID program during Fiscal Year 1994. In Fiscal Year 1995, these activities are transitioning into the Landfill Stabilization Focus Area.
\end{abstract}





\section{SUMMARY}

This report summarizes the activities of the U.S. Department of Energy's (DOE's) Buried Waste Integrated Demonstration (BWID) for FY-94 activities. The mission of BWID is to support the development of a multitude of technologies for effective and efficient remediation of buried waste throughout the DOE complex. BWID evaluates, demonstrates, and validates technologies and transfers this information and equipment to DOE and private industry to support remediation planning and implementation.

BWID continues to perform research and evaluation of numerous technologies in the areas of characterization, retrieval, assay, contamination control, and treatment. In FY-95, BWID activities will transition into the Landfill Stabilization Focus Area. In the characterization area, the focus is on improving sensitivity, range, response time, and cost of subsurface imaging. In buried waste retrieval, the focus is on precision, remote operations, productivity, and cost. In assay, research is focused on a variety of species assayed, sensitivity, portability, response time, and cost. In contamination control, the focus is on fixing/stabilizing the source, controlling the spread of contaminants, compatibility with other operations, and cost. In the treatment area, the focus is on process robustness with regard to input waste diversity, effectiveness of the treatment, verification of the process, and cost.

BWID has obtained the support of universities, private industry, other national laboratories, and other Federal agencies in the development of these technologies. In FY-94, there were 17 industry/university partnerships, nine national laboratory partners, and partnerships with the U.S. Bureau of Mines, U.S. Geological Survey, and Department of Defense.

The FY-94 budget for BWID totaled $\$ 23.9$ million, supported 49 Technical Task Plans (TTPs), and involved six DOE field offices. Of the total budget, $\$ 3.3$ million was carried over from FY-93, most of which was part of a $\$ 3.5$ million allocation late in the fourth quarter of FY-93. Of the $\$ 23.9$ million, $71 \%$ or $\$ 16.9$ million of the funding was associated with the DOE Idaho Operations Office. Of the $\$ 16.9$ million, approximately $\$ 4.1$ million or $24 \%$ was subcontracted to the private sector, universities, or other Federal agencies. Of the $\$ 7$ million going to other DOE operations offices, $\$ 1$ million or $14 \%$ was subcontracted to the private sector or universities.

BWID demonstrated and evaluated a number of technologies in FY-94. These demonstrations included characterization, retrieval, contamination control, and treatment activities. BWID placed increased emphasis on passing these technologies to private industries so that they could respond to requests to remediate specific waste sites in the future. A detailed review of these technologies is presented in section 3 .

BWID has established a public participation policy with the goal of providing stakeholders timely and accurate information and meaningful opportunities for involvement in the technology development and demonstration process. During 1994, presentations were made to civic, educational, and technical groups; displays and posters were viewed nationally; regular media contacts were established; and video teleconferences were held to enhance communication. 
BWID sponsored a Technology Exhibition and Equipment Display in Idaho Falls, August 8-9, 1994, featuring the technologies involved with the integrated demonstration. The exhibition provided a forum to enhance the interaction between public and private sectors. There were 212 participants, including 77 representatives from industry, 6 representatives from academia, 25 participants from DOE EM-40 and EM-50, 92 participants from national laboratory contractors, and 12 participants from other government agencies.

BWID established the Technical and Academic Review Group to provide independent technical oversight and guidance to the BWID technology selection, development, and demonstration processes. BWID also enhanced the exchange of information within EM-40 by funding EM-40 representatives from Oak Ridge, Savannah River, Hanford, and the INEL to participate in the planning and review of current and future BWID technological advancements.

Technology transfer and commercialization activities were also enhanced by the development of commercialization implementation plans for selected BWID technologies and through BWID-sponsored industry and technology transfer workshops. 


\section{CONTENTS}

ABSTRACT $\ldots \ldots \ldots \ldots \ldots \ldots \ldots \ldots \ldots \ldots \ldots \ldots \ldots \ldots \ldots \ldots \ldots \ldots \ldots \ldots \ldots \ldots \ldots \ldots$ iii

SUMMARY $\ldots \ldots \ldots \ldots \ldots \ldots \ldots \ldots \ldots \ldots \ldots \ldots \ldots \ldots \ldots \ldots \ldots \ldots \ldots \ldots \ldots \ldots, \mathbf{v}$

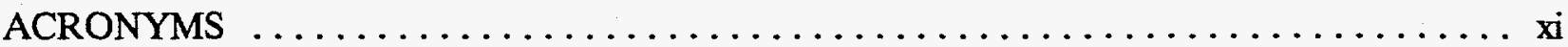

1. INTRODUCTION $\ldots \ldots \ldots \ldots \ldots \ldots \ldots \ldots \ldots \ldots \ldots \ldots \ldots \ldots \ldots \ldots \ldots \ldots \ldots$

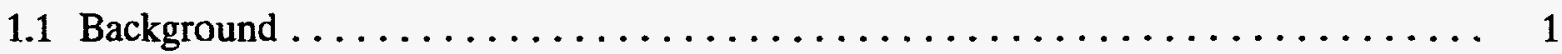

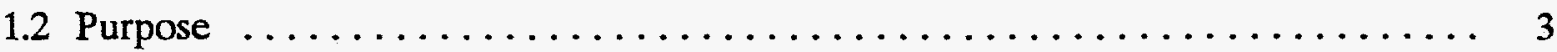

2. MANAGEMENT APPROACH $\ldots \ldots \ldots \ldots \ldots \ldots \ldots \ldots \ldots \ldots \ldots \ldots \ldots \ldots \ldots \ldots \ldots \ldots$

3. TECHNICAL ACCOMPLISHMENTS $\ldots \ldots \ldots \ldots \ldots \ldots \ldots \ldots \ldots \ldots \ldots \ldots \ldots$

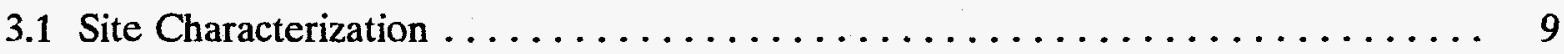

3.1.1 Nonintrusive Sensing of Environmentally Important Objects-AL911201 _ 9

3.1.2 Electrothermal Hollow Cathode Discharge Spectrometry-CH121201 . . . 10

3.1.3 Nonintrusive Characterization Studies-ID121112 . . . . . . . . . . . 11

3.1.4 Field Demonstration of Characterization Technologies-ID121213 . . . . 12

3.1.5 BWID Dig-Face Characterization-ID132003 . . . . . . . . . . . 13

3.1.6 Electromagnetic Imaging as Applied to Mapping and Characterization of

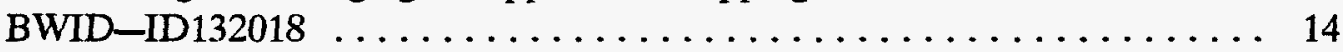

3.1.7 Geophysical Workshop-ID132019 . . . . . . . . . . . . . . 15

3.1 .8 Imaging Infrared Interferometer-ID142003 $\ldots \ldots \ldots \ldots \ldots \ldots \ldots \ldots \ldots$

3.1.9 Very Early Time Electromagnetics-ID142004 . . . . . . . . . . . . 15

3.1.10 Virtual Environment Generation of Buried Waste-ID142005 . . . . . . 16

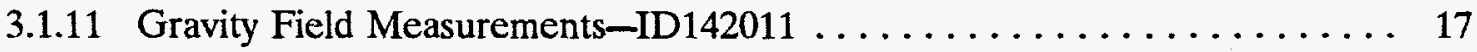

3.1.12 Geophysics Airborne Platforms-ID142017 . . . . . . . . . . . . . 18

3.1.13 Ground-Penetrating Radar Research Consortium-ID142018 . . . . . . . 18

3.1.14 High-Resolution Imaging of Buried Waste Using Radar Array-RL342002 . 19

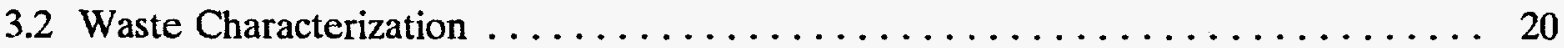

3.2.1 Improved TRU Waste Assay (CTEN)-AL132012 . . . . . . . . . . 20

3.2.2 Radiological and Hazardous Materials Measurement System-ID121212 . . 21

3.2.3 Hazardous and Chemical Waste Separation at RWMC Excavation Sites-ID132021 . . . . . . . . . . . . . . . . . . . . . 22

3.2.4 Excavated Waste Assay-ID142015 . . . . . . . . . . . . . . . . 22

3.2.5 High-Speed Digital Radiography and Computed Tomography of Waste Drums-ID142016 ........................... 23

3.2.6 Nondestructive Assay/Nondestructive Examination of Low Level Waste Drums-SF221209 
3.3.1 Mobile Rapid TRU Monitoring Laboratory-ID121210 . . . . . . . . . 24

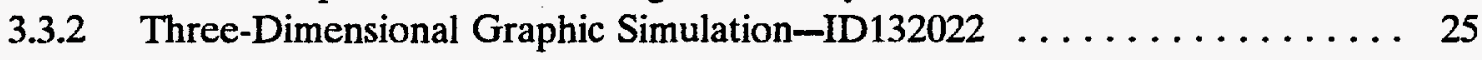

3.3.3 Real-Time Monitoring of Transuranic Dust-ID142002 . . . . . . . . 26

3.3.4 Waste Conveyance for Buried Waste and Retrieval End Effector-ID142006/ID142007 . . . . . . . . . . . . . . . 27

3.3.5 Remote Retrieval Demonstration-ID142008 . . . . . . . . . . . . 28

3.3.6 Cooperative Telerobotic Retrieval-ID142009 ... . . . . . . . . . . 29

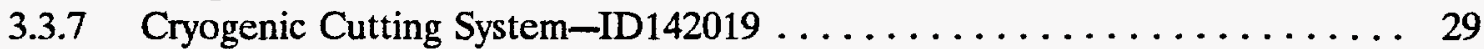

3.3.8 Machine Health Monitoring-ID142020 . . . . . . . . . . . . 30

3.3.9 Remote Excavation Demonstration at Oak Ridge-OR142003 . . . . . . . 31

3.3.10 Contaminated Material Excavation, Handling and Retrieval System-RL342001 . . . . . . . . . . . . . . . . . 32

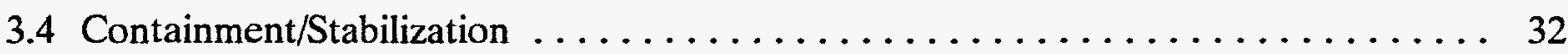

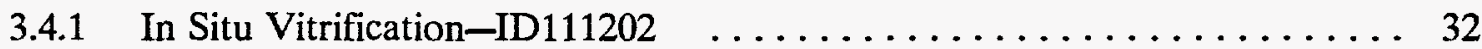

3.4.2 In Situ Encapsulation of Buried Waste-ID142012 . . . . . . . . . 32

3.4.3 Innovative Grout Demonstration-ID142014 . . . . . . . . . . 33

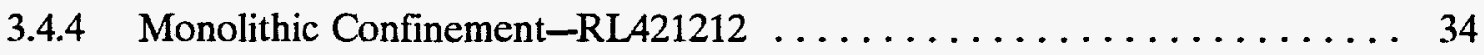

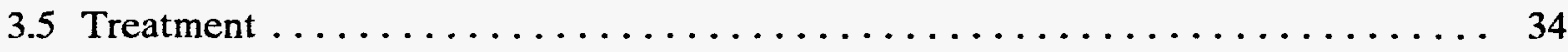

3.5.1 Secondary Treatment of BWID Off-Gas Using Nonthermal

Plasma-AL142002 . . . . . . . . . . . . . . . . . . . . . . . . 34

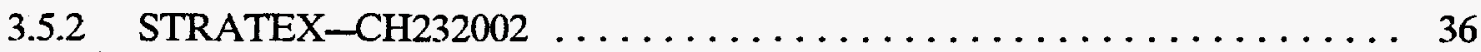

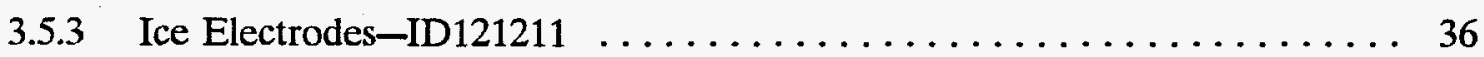

3.5.4 BWID Waste Form Integration and Limits-ID132006 . . . . . . . . . 37

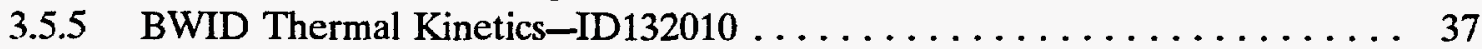

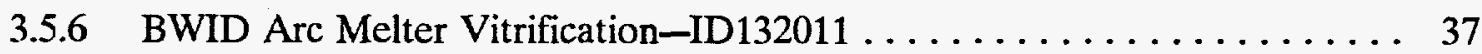

3.5.7 Modeling of Thermal Plasma Arc Technology-ID142010 . . . . . . . . 38

3.5.8 Graphite DC Arc Plasma Furnace and Diagnostics-RL321211 . . . . . 39

3.6 Programmatic $\ldots \ldots \ldots \ldots \ldots \ldots \ldots \ldots \ldots \ldots \ldots \ldots \ldots \ldots \ldots \ldots \ldots$

3.6.1 BWID Program Coordination-ID132008 . . . . . . . . . . . . 41

3.6.2 BWID Technical and Academic Review Group-ID132015 . . . . . . 42

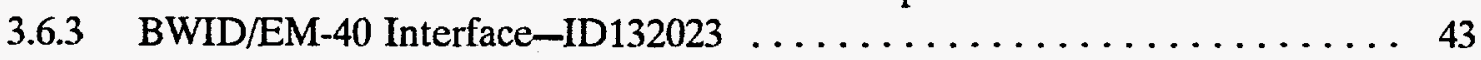

3.6.4 BWID Technology Deployment-ID142013 . . . . . . . . . . . . 44

3.6.5 BWID Technology Acceptance and Oversight-ID142022 . . . . . . . 44

3.6.6 Technology Implementation and Public Participation-ID144101 . . . . 45

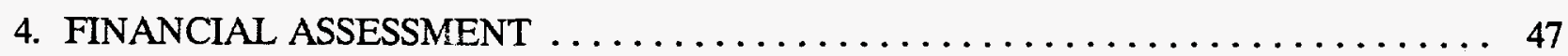

Appendix A-List of Buried Waste Integrated Demonstration FY-94 Reports . . . . . . . A-1 
Appendix B-List of FY-94 Technology Transfer Activities (Partnerships, Subcontracts, Licenses, CRADAs, Patents, Non-DOE Federal Agency Agreements, etc.) . . . . . . B-1

\section{TABLES}

1. BWID FY-94 financial summary $\ldots \ldots \ldots \ldots \ldots \ldots \ldots \ldots \ldots \ldots \ldots \ldots \ldots$ 



\section{ACRONYMS}

A\&P CT active and passive computed tomography

AGV automatically guided vehicle

ASME American Society of Mechanical Engineers

ATR automatic target recognition

BWID Buried Waste Integrated Demonstration

CAM continuous air monitor

CAT computer-automated tomography

CERCLA Comprehensive Environmental Response, Compensation, and Liability Act

CRADA

CT

CTEN Cooperative Research and Development Agreement computed tomography

combined thermal/epithermal neutron

$\mathrm{DC}$

direct current

DOE U.S. Department of Energy

DOE-ID U.S. Department of Energy Idaho Operations Office

DOIT Develop Onsite Technologies

DR digital radiography

DSIT

Demonstration Site Implementation Team

EM

electromagnetic

EM-30

DOE Headquarters Waste Management

EM-40

DOE Headquarters Environmental Restoration

EM-50

EPA

DOE Headquarters Technology Development

ER U.S. Environmental Protection Agency

$\mathrm{ER} / \mathrm{WM}$

Environmental Restoration

Environmental Restoration and Waste Management

FDEM frequency domain electromagnetics

FY

fiscal year

GPH ground-penetrating holographic

GPR

ground-penetrating radar

HECS Human Engineered Control Station

HEPA high-efficiency particulate air

HFS high-frequency sounder

IDC integrated demonstration coordinator

INEL Idaho National Engineering Laboratory

ISV in situ vitrification

LIBS laser-induced breakdown spectroscopy

LINAC linear accelerator 


\begin{tabular}{|c|c|}
\hline $\begin{array}{l}\text { LLNL } \\
\text { LLW } \\
\text { LSV }\end{array}$ & $\begin{array}{l}\text { Lawrence Livermore National Laboratory } \\
\text { low-level radioactive waste } \\
\text { low-signature vehicle }\end{array}$ \\
\hline MIT & Massachusetts Institute of Technology \\
\hline NTP & nonthermal plasma \\
\hline ORNL & Oak Ridge National Laboratory \\
\hline $\begin{array}{l}\text { PCF } \\
\text { PI } \\
\text { PNL }\end{array}$ & $\begin{array}{l}\text { plasma centrifugal furnace } \\
\text { principal investigator } \\
\text { Pacific Northwest Laboratory }\end{array}$ \\
\hline $\begin{array}{l}\text { RCRA } \\
\text { RCS } \\
\text { RES } \\
\text { RGS } \\
\text { RTDM } \\
\text { RTML } \\
\text { RWMC }\end{array}$ & $\begin{array}{l}\text { Resource Conservation and Recovery Act } \\
\text { Remote Characterization System } \\
\text { Remote Excavation System } \\
\text { rapid geophysical surveyor } \\
\text { real-time dust monitor } \\
\text { Rapid Transuranic Monitoring Laboratory } \\
\text { Radioactive Waste Management Complex }\end{array}$ \\
\hline $\begin{array}{l}\text { SCS } \\
\text { SEM } \\
\text { SBPD }\end{array}$ & $\begin{array}{l}\text { Supervisory Control System } \\
\text { scanning electron microscope } \\
\text { simulation-based planning and design }\end{array}$ \\
\hline $\begin{array}{l}\text { TARG } \\
\text { 3DDST } \\
\text { TDEM } \\
\text { TL } \\
\text { TMG } \\
\text { TRU } \\
\text { TTP }\end{array}$ & $\begin{array}{l}\text { Technical and Academic Review Group } \\
\text { Three-Dimensional Dynamic Simulation Tool } \\
\text { time domain electromagnetics } \\
\text { technical liaison } \\
\text { tensor magnetic gradiometer } \\
\text { transuranic } \\
\text { Technical Task Plan }\end{array}$ \\
\hline $\begin{array}{l}\text { USBM } \\
\text { USGS }\end{array}$ & $\begin{array}{l}\text { U.S. Bureau of Mines } \\
\text { U.S. Geological Survey }\end{array}$ \\
\hline $\begin{array}{l}\text { VETEM } \\
\text { VOC }\end{array}$ & $\begin{array}{l}\text { very early time electromagnetics } \\
\text { volatile organic compound }\end{array}$ \\
\hline $\begin{array}{l}\text { WGA } \\
\text { WHC } \\
\text { WM }\end{array}$ & $\begin{array}{l}\text { Western Governors' Association } \\
\text { Westinghouse Hanford Company } \\
\text { Waste Management }\end{array}$ \\
\hline
\end{tabular}




\section{Buried Waste Integrated Demonstration Fiscal Year 1994 Close-Out Report}

\section{INTRODUCTION}

\subsection{Background}

The amount of buried waste located throughout the U.S. Department of Energy (DOE) complex is estimated at approximately 3.1 million $\mathrm{m}^{3}$ (DOE Complex Buried Waste Assessment, PNL-8390, January 1993). The DOE sites where this waste is predominantly located are Hanford, Savannah River, Idaho (INEL), Los Alamos, Oak Ridge (X-10), and Rocky Flats. The wastes at these sites have been buried or stored in several types of structures, including trenches, pits, buildings, and storage pads.

Approximately half of all DOE buried waste was disposed before 1970 in accordance with regulations of the time. Disposal regulations at that time permitted the commingling of various wastes [transuranic (TRU), low-level radioactive (LLW), and hazardous]. As a result, much of the buried waste throughout the DOE complex is presently believed to be contaminated with both hazardous and radioactive materials. DOE buried waste typically includes TRU-contaminated radioactive waste, LLW, hazardous waste per 40 CFR 261, greater-than-Class C waste per 10 CFR 61.55, mixed TRU waste, and mixed LLW. Interstitial soils are also believed to be contaminated as a result of these disposal practices, which significantly increase the volume of materials requiring remediation.

Typical buried waste includes construction and demolition materials (lumber, concrete blocks, steel plates, etc.), laboratory equipment (hoods, desks, tubing, glassware, gloves, etc.), process equipment (heat exchangers, valves, ion exchange resins, high-efficiency particulate air filters, etc.), maintenance equipment (hand tools, cranes, oils and greases, etc.), and decontamination materials (paper, rags, gloves, plastic bags).

Waste and site characteristics of the INEL Radioactive Waste Management Complex (RWMC) are generally representative of other DOE buried waste sites. Therefore, remediation technology demonstrations performed at the INEL will be transferable for potential applications at other DOE buried waste sites. Approximately 0.3 million $\mathrm{m}^{3}$ of waste is buried at RWMC in containers such as steel drums $(30,40$, and $55 \mathrm{gal})$, cardboard cartons, and wooden boxes (up to $105 \times 105 \times 214 \mathrm{in}$.). Larger individual items were disposed of separately as loose trash.

Degradation of the waste containers is believed to have resulted in contamination of surrounding soil. Estimates of contaminated soils are approximately 0.9 million $\mathrm{m}^{3}$.

In the past, incomplete records were kept. As a result, the exact nature of the contamination is uncertain. Over the years, some of the waste-containing drums and boxes have breached, creating new problems. Some have potentially contaminated groundwater.

These waste disposal sites must be remediated or cleaned up within the existing and evolving statutory and regulatory requirements. These requirements may include the Federal Facility 
Agreement and Consent Order; Comprehensive Environmental Response, Compensation, and Liability Act (CERCLA); Resource Conservation and Recovery Act (RCRA); and other interagency agreements with legally binding milestones.

Buried waste presents significant remediation challenges, particularly waste buried prior to 1970. DOE is committed to remediating the problems that resulted from past disposal practices. In an effort to focus resources and address these opportunities, the DOE Office of Technology Development has developed integrated programs and demonstrations. The integrated program is the cost-effective mechanism that assembles a group of related technologies to evaluate their performance to solve a specific aspect of a waste management or environmental problem. The integrated demonstration is the cost-effective mechanism that assembles a group of related technologies to evaluate their performance individually or as a complete system in correcting waste management and environmental problems.

The INEL, which has a significant portion of the DOE TRU buried waste, has been chosen as the lead site for the Buried Waste Integrated Demonstration (BWID) to demonstrate emerging technologies that offer promising solutions to problems associated with remediating buried waste. BWID addresses the difficult remediation problems associated with DOE complex-wide buried waste, particularly TRU-contaminated buried waste.

BWID focuses on the remedial technology application needs of Environmental Restoration and Waste Management (ER/WM). ER/WM sites from across the DOE complex are frequently assessed. Their needs define remedial technology areas where inadequate, marginal, or no technology exists, and the timeframe available to provide input to the remedial decision processes. Technology development and demonstration proposals are solicited and evaluated by BWID to determine their potential to support the ER/WM applications. The timeframe prior to ER/WM decision milestones is considered by BWID to be the window of opportunity for development of more cost-effective and efficient solutions.

A detailed system analysis was initiated in FY-92 and is being used to identify and develop high-level systems for remediating buried wastes. The BWID system's approach defines the functions that need to be performed by remedial technologies. This approach encompasses the entire remediation process from characterization to postmonitoring. The development and demonstration of the technology is predicated on how a technology fits into the total remediation process. To address all of these technological issues, BWID has enlisted scientific expertise of individuals and groups from within the DOE complex as well as experts from universities, private industry, and the international community.

Technology development and demonstration activities sponsored by BWID are based on their potential contribution to the overall system as well as on individual performance potential. These activities are guided by technical objectives derived from performance needs of the system. During testing, technologies are evaluated against technology-specific performance objectives and high-level system objectives to assess both individual technology performance and impact on the overall system.

Technology performance tests are conducted to evaluate a technology's performance relative to the technical objectives. The performance tests were valuable in obtaining technology-specific 
data on a technology's effectiveness, implementability, and cost. BWID provides this information to potential end users such as ER/WM to assist them in remedial planning and feasibility studies. As technology data are infused into the ER/WM planning cycle, the probability that the technology will be of benefit to the remediation efforts is enhanced. In this manner, BWID technologies are being considered for application or are in use by ER/WM. BWID has already contributed to remediation efforts at Hanford, Oak Ridge, INEL, and Los Alamos.

As technology development approaches the demonstration stage, BWID conducts demonstrations in an integrated fashion. This provides a cost-effective method to evaluate the performance of technologies in simulated real-life conditions. These demonstrations provide the opportunity to evaluate not only the individual performance of a technology, but also the performance of all or portions of the complete remediation system.

Technologies are evaluated against the technical objectives defined by the remediation system and ER/WM needs. The BWID Technical Support Group provides technical guidance toward meeting those DOE ER/WM needs and consists of representatives from Environmental Restoration and Waste Management Programs at Oak Ridge, Savannah River, INEL, and Hanford. Technology evaluations are conducted using guidance similar to the CERCLA Feasibility Study guidance for the detailed analysis of remedial alternatives and technology options. Use of technology evaluation criteria guidance as set forth by CERCLA enhances regulatory and stakeholder acceptance of demonstrated technologies. To further enhance technology acceptance, BWID established an independent technical review entity called the Technical and Academic Review Group (TARG) in FY-94, comprising representatives from academia and non-DOE federal agencies to provide critical technical review of BWID-sponsored technologies. Published BWID technology evaluation reports become reference sources for $\mathrm{ER} / \mathrm{WM}$ decision analyses.

The goal of BWID is to determine the threshold of capability for emerging technologies. Technologies have been identified, screened for applicability to the identified needs and requirements, selected for demonstration, and evaluated based on prescribed performance objectives. This effort will determine implementability, effectiveness, potential schedule reduction, and cost savings associated with emerging technology to shape remediation plans and implementation of the environmental restoration of buried waste.

\subsection{Purpose}

The purpose of this document is to summarize activities of the FY-94 BWID program. This summary is not intended to be an extended review of all activities but rather a highlight of significant technical accomplishments for each FY-94 BWID-sponsored Technical Task Plan (TTP). A financial summary of the entire program is also presented in Table 1. Supporting information, such as the reports produced and list of university/industry participants, is included in Appendices A and B. In FY-95, BWID activities will be transitioned into the Landfill Stabilization Focus Area. 
Table 1. BWID FY-94 financial summary.

\begin{tabular}{|c|c|c|c|c|c|c|}
\hline TTP No. & TTP Title & Site & $\begin{array}{c}\text { FY-94 } \\
\text { total } \\
\text { funding } \\
\text { available } \\
(\$ \mathrm{KK})^{\mathrm{a}}\end{array}$ & $\begin{array}{l}\text { Budgeted } \\
\text { cost of } \\
\text { work } \\
\text { scheduled } \\
\text { (\$K) }\end{array}$ & $\begin{array}{l}\text { Budgeted } \\
\text { cost of } \\
\text { work } \\
\text { performed } \\
\text { (\$K) }\end{array}$ & $\begin{array}{c}\text { Actual } \\
\text { cost of } \\
\text { work } \\
\text { performed } \\
\text { (\$K) }\end{array}$ \\
\hline AL132012 & $\begin{array}{l}\text { Combined Thermal and } \\
\text { Epithermal Neutron } \\
\text { (CTEN) Assay }\end{array}$ & Los Alamos & 916 & 899 & 865 & 836 \\
\hline AL142002 & $\begin{array}{l}\text { Treatment of BWID } \\
\text { Off-Gas Using Nonthermal } \\
\text { Plasma }\end{array}$ & Los Alamos & 240 & 292 & 135 & 194 \\
\hline AL911201 & $\begin{array}{l}\text { Nonintrusive Sensing of } \\
\text { Environmentally Important } \\
\text { Objects }\end{array}$ & $\begin{array}{l}\text { Grand } \\
\text { Junction }\end{array}$ & 1,191 & 899 & 284 & 313 \\
\hline CH121201 & $\begin{array}{l}\text { Electrothermal Hollow } \\
\text { Cathode Discharge } \\
\text { Spectrometry }\end{array}$ & Ames & 236 & 236 & 98 & 221 \\
\hline $\mathrm{CH} 232002$ & STRATEX & $\begin{array}{l}\text { Argonne- } \\
\text { East }\end{array}$ & 325 & 325 & 0 & 190 \\
\hline ID111202 & In Situ Vitrification & INEL & 17 & 17 & 15 & 4 \\
\hline ID121112 & $\begin{array}{l}\text { INEL Nonintrusive } \\
\text { Characterization and } \\
\text { Sensing of Buried Objects }\end{array}$ & INEL & 121 & 121 & 121 & 80 \\
\hline ID121210 & $\begin{array}{l}\text { Mobile Transuranic } \\
\text { Monitoring Laboratory }\end{array}$ & INEL & 725 & 725 & 557 & 666 \\
\hline ID121211 & Ice Electrodes & INEL & 176 & 161 & 50 & 44 \\
\hline ID121212 & $\begin{array}{l}\text { Radiological and } \\
\text { Hazardous Materials } \\
\text { Measurement System }\end{array}$ & INEL & 691 & 685 & 502 & 480 \\
\hline ID121213 & $\begin{array}{l}\text { Field Demonstration of } \\
\text { Characterization Studies }\end{array}$ & INEL & 163 & 163 & 140 & 154 \\
\hline ID132003 & $\begin{array}{l}\text { BWID Dig-Face } \\
\text { Characterization }\end{array}$ & INEL & 1,168 & 1,064 & 1,045 & 999 \\
\hline ID132006 & $\begin{array}{l}\text { BWID Waste Form } \\
\text { Integration and Limits }\end{array}$ & INEL & 96 & 95 & 91 & 84 \\
\hline ID132008 & $\begin{array}{l}\text { BWID Program } \\
\text { Coordination }\end{array}$ & INEL & 1,110 & 1,089 & 1,085 & 1,087 \\
\hline ID132010 & BWID Thermal Kinetics & INEL & 21 & 21 & 20 & 19 \\
\hline ID132011 & $\begin{array}{l}\text { BWID Arc Melter } \\
\text { Vitrification }\end{array}$ & INEL & 1,170 & 1,170 & 630 & 663 \\
\hline ID132015 & $\begin{array}{l}\text { BWID Technical and } \\
\text { Academic Review Group }\end{array}$ & INEL & 429 & 429 & 425 & 406 \\
\hline
\end{tabular}


Table 1. (continued).

\begin{tabular}{|c|c|c|c|c|c|c|}
\hline TTP No. & TTP Title & Site & $\begin{array}{c}\text { FY-94 } \\
\text { total } \\
\text { funding } \\
\text { available } \\
(\$ K)^{\mathrm{a}}\end{array}$ & $\begin{array}{l}\text { Budgeted } \\
\text { cost of } \\
\text { work } \\
\text { scheduled } \\
\text { (\$K) }\end{array}$ & $\begin{array}{l}\text { Budgeted } \\
\text { cost of } \\
\text { work } \\
\text { performed } \\
\text { (\$K) }\end{array}$ & $\begin{array}{l}\text { Actual } \\
\text { cost of } \\
\text { work } \\
\text { performed } \\
\quad(\$ K)\end{array}$ \\
\hline ID132018 & $\begin{array}{l}\text { Electromagnetic Imaging as } \\
\text { Applied to Mapping and } \\
\text { Characterization of BWID }\end{array}$ & INEL & 93 & 93 & 79 & 57 \\
\hline ID132019 & Geophysical Workshop & INEL & 3 & 20 & $\mathbf{0}$ & 3 \\
\hline ID132021 & $\begin{array}{l}\text { Hazardous and Chemical } \\
\text { Waste Separation at } \\
\text { RWMC Excavation Sites }\end{array}$ & INEL & 153 & 156 & 156 & 150 \\
\hline ID132022 & $\begin{array}{l}\text { Three-Dimensional } \\
\text { Dynamic Graphic } \\
\text { Simulation }\end{array}$ & INEL & 64 & 64 & 64 & 62 \\
\hline ID132023 & BWID EM-40 Interface & INEL & 74 & 74 & 74 & 63 \\
\hline ID142002 & $\begin{array}{l}\text { Real-Time Monitoring of } \\
\text { Transuranic-Contaminated } \\
\text { Dust }\end{array}$ & INEL & 390 & 390 & 349 & 361 \\
\hline ID142003 & $\begin{array}{l}\text { Imaging Infrared } \\
\text { Interferometer }\end{array}$ & INEL & 400 & 400 & 298 & 292 \\
\hline ID142004 & $\begin{array}{l}\text { Very Early Time } \\
\text { Electromagnetics } \\
\text { (VETEM) }\end{array}$ & INEL & 644 & 660 & 660 & 570 \\
\hline ID142005 & $\begin{array}{l}\text { Virtual Environment } \\
\text { Generation of Buried } \\
\text { Waste }\end{array}$ & INEL & 854 & 878 & 877 & 806 \\
\hline ID142006 & $\begin{array}{l}\text { Waste Conveyance for } \\
\text { Buried Waste }\end{array}$ & INEL & 650 & 619 & 547 & 638 \\
\hline ID142007 & $\begin{array}{l}\text { Retrieval Technology - End } \\
\text { Effector }\end{array}$ & INEL & 532 & 532 & 467 & 394 \\
\hline ID142008 & $\begin{array}{l}\text { Full-Scale Remote } \\
\text { Retrieval Demonstration }\end{array}$ & INEL & 802 & 718 & 799 & 719 \\
\hline ID142009 & $\begin{array}{l}\text { Cooperative Telerobotic } \\
\text { Retrieval }\end{array}$ & INEL & 1,131 & 1,311 & 1,104 & 1,087 \\
\hline ID142010 & $\begin{array}{l}\text { Modeling of Thermal } \\
\text { Plasma Arc Technology }\end{array}$ & INEL & 350 & 350 & 350 & 350 \\
\hline ID142011 & $\begin{array}{l}\text { Gravity Field } \\
\text { Measurements }\end{array}$ & INEL & 131 & 131 & 131 & 131 \\
\hline ID142012 & $\begin{array}{l}\text { In Situ Encapsulation of } \\
\text { Buried Waste }\end{array}$ & INEL & 363 & 363 & 351 & 326 \\
\hline
\end{tabular}


Table 1. (continued).

\begin{tabular}{|c|c|c|c|c|c|c|}
\hline TTP No. & TTP Title & Site & $\begin{array}{c}\text { FY-94 } \\
\text { total } \\
\text { funding } \\
\text { available } \\
(\$ \mathrm{~K})^{\mathrm{a}}\end{array}$ & $\begin{array}{l}\text { Budgeted } \\
\text { cost of } \\
\text { work } \\
\text { scheduled } \\
\text { (\$K) }\end{array}$ & $\begin{array}{l}\text { Budgeted } \\
\text { cost of } \\
\text { work } \\
\text { performed } \\
\quad(\$ K)\end{array}$ & $\begin{array}{c}\text { Actual } \\
\text { cost of } \\
\text { work } \\
\text { performed } \\
(\$ K)\end{array}$ \\
\hline ID142013 & Technology Deployment & INEL & 1,438 & 1,534 & 1,454 & 1,400 \\
\hline ID142014 & $\begin{array}{l}\text { Innovative Grout } \\
\text { Demonstration }\end{array}$ & INEL & 383 & 383 & 372 & 379 \\
\hline ID142015 & $\begin{array}{l}\text { Excavated Waste Assay } \\
\text { (EWA) }\end{array}$ & INEL & 400 & 400 & 364 & 302 \\
\hline ID142016 & $\begin{array}{l}\text { High-Speed Digital } \\
\text { Radiography \& Computed } \\
\text { Tomography of Waste } \\
\text { Drums }\end{array}$ & INEL & 831 & 831 & 789 & 731 \\
\hline ID142017 & $\begin{array}{l}\text { Geophysics Airborne } \\
\text { Platforms }\end{array}$ & INEL & 23 & 23 & 17 & 16 \\
\hline ID142018 & $\begin{array}{l}\text { Ground-Penetrating Radar } \\
\text { Research Consortium }\end{array}$ & INEL & 197 & 157 & 130 & 103 \\
\hline ID142019 & $\begin{array}{l}\text { Cryogenic Cutting System } \\
\text { Demonstration }\end{array}$ & INEL & 395 & 395 & 390 & 371 \\
\hline ID142020 & $\begin{array}{l}\text { Machine Health } \\
\text { Monitoring }\end{array}$ & INEL & 540 & 540 & 522 & 507 \\
\hline ID142022 & $\begin{array}{l}\text { Technology Acceptance } \\
\text { and Oversight }\end{array}$ & INEL & 146 & 146 & 131 & 136 \\
\hline ID $144101^{b}$ & $\begin{array}{l}\text { Technology } \\
\text { Implementation and Public } \\
\text { Participation }\end{array}$ & INEL & 184 & 184 & 185 & 182 \\
\hline OR142003 & Remote Excavation System & INEL & 300 & 300 & 300 & 262 \\
\hline RL321211 & Graphite DC Arc Plasma & PNL & 1,758 & 1,780 & 1,293 & 855 \\
\hline RL342001 & $\begin{array}{l}\text { Contaminated Material, } \\
\text { Excavation, Handling, and } \\
\text { Retrieval System }\end{array}$ & PNL & 200 & 200 & 200 & 194 \\
\hline RL342002 & $\begin{array}{l}\text { High-Resolution Imaging } \\
\text { of Buried Waste Using } \\
\text { Radar Array }\end{array}$ & PNL & 496 & 496 & 468 & 464 \\
\hline RL421212 & Monolithic Confinement & PNL & 465 & 481 & 295 & 323 \\
\hline SF221209 & $\begin{array}{l}\text { Nondestructive } \\
\text { Assay/Nondestructive } \\
\text { Examination of Low-Level } \\
\text { Waste Drums }\end{array}$ & LLNL & 794 & 794 & 690 & 684 \\
\hline
\end{tabular}


Table 1. (continued).

\begin{tabular}{|c|c|c|c|c|c|c|}
\hline TTP No. & TTP Title & Site & $\begin{array}{c}\text { FY-94 } \\
\text { total } \\
\text { funding } \\
\text { available } \\
(\$ K)^{\mathrm{a}}\end{array}$ & $\begin{array}{l}\text { Budgeted } \\
\text { cost of } \\
\text { work } \\
\text { scheduled } \\
\text { (\$K) }\end{array}$ & $\begin{array}{l}\text { Budgeted } \\
\text { cast of } \\
\text { work } \\
\text { performed } \\
(\$ K)\end{array}$ & $\begin{array}{c}\text { Actual } \\
\text { cost of } \\
\text { work } \\
\text { performed } \\
\text { (\$K) }\end{array}$ \\
\hline SF232001 & $\begin{array}{l}\text { Remote Characterization } \\
\text { System }\end{array}$ & LLNL & 95 & 95 & 95 & 95 \\
\hline \multicolumn{7}{|c|}{ Note: Values are from September 1994 financial data. } \\
\hline \multicolumn{7}{|c|}{ a. Includes FY-93 carryover dollars. } \\
\hline \multicolumn{7}{|c|}{ b. Funds from DOE Office of Technology Transfer. } \\
\hline
\end{tabular}




\section{MANAGEMENT APPROACH}

To ensure that the project was managed in an efficient and effective manner, a BWID Program Office was organized at the INEL in FY-91. Management guidance was developed to implement a system that ensured successful deployment of technologies. This approach assumed the responsibility for facilities, operations, regulatory compliance, and public involvement activities by the BWID Program Office. Centralization of these activities resulted in a reduction in the cost of deployment and provided assurance that technologies would get to the field as planned. The BWID Program Office staff was established as an interdisciplinary team employing numerous quality-improvement tools to ensure its effectiveness.

Early in development, it was recognized that effective communication and good project management were key in a successful BWID program. To ensure effective communication, frequent meetings were held between the DOE Headquarters program manager, DOE Idaho Operations Office (DOE-ID) technical program officer, and BWID integrated demonstration coordinator (IDC). Additional communication mechanisms were identified to enhance communication between the Program Office and the ER/WM customer, and between the Program Office and the principal investigators (PIs).

A new management structure for the Program Office was implemented in FY-94. The IDC is supported by a systems integration program manager and a technology deployment manager. In addition, a TARG was formed consisting of experts from specific technical areas pertinent to BWID. The members represented organizations throughout private industry, academia, and non-DOE federal agencies. This new group provided the BWID program with independent technology reviews of current and proposed technologies. The BWID Technical Support Group (TSG) provided technical guidance toward meeting ER/WM needs and comprised representatives from ER/WM programs at Oak Ridge, Savannah River, INEL, and Hanford. 


\section{TECHNICAL ACCOMPLISHMENTS}

Five major technical areas (site characterization, waste characterization, retrieval, containment/stabilization, and treatment) and a programmatic area were involved with the FY-94 BWID program. While the technical areas were specific for technology development and demonstration, the programmatic activities provided a more detailed assessment of the DOE complex buried waste problem as well as systematic approaches for satisfying technological deficiencies and technology acceptance of BWID developed technologies. A summary of accomplishments for each TTP is provided by technical area in the following sections.

\subsection{Site Characterization}

\subsubsection{Nonintrusive Sensing of Environmentally Important Objects-AL911201}

This activity was initiated in FY-92 and is continuing through FY-95. This program consists of two subtasks as described below:

\section{Site Characterization Using the Tensor Magnetic Gradiometer (TMG) System}

The objective of this subtask is to develop an improved system for nonintrusive site characterization through measurement and interpretation of the magnetic gradient tensor. This technique provides more information about buried magnetic objects than measurements of a single component of the magnetic field or its gradient. Thus, a field system that measures the magnetic gradient tensor will significantly improve survey efficiency and quantitative interpretation. The system consists of an array of four high-sensitivity triaxial ringcore fluxgate magnetometers and supporting hardware.

\section{Accomplishments}

- The basic TMG system hardware was completed

- Software for data acquisition, basic data reduction, and elementary interpretation was completed. The system was field tested during FY-94.

Results of these activities are documented in reports summarized in Appendix A.

\section{Three-Dimensional Site Characterization Using Broadband Electromagnetics}

Broadband electromagnetics include the development of instrumentation and advanced data reduction methods able to acquire and interpret electromagnetic data over an extended band of frequencies or, in the case of time-domain measurements, time. Monitoring and characterization of a dig face requires an electromagnetic (EM) antenna array, which is optimized for performing shallow high-resolution soil conductivity and metal detection measurements while the sensor is continuously being moved over the dig face. 


\section{Accomplishments}

- Broadband electromagnetics data have been collected and analyzed using commercially available software.

- Data are being analyzed using advanced state-of-the-art methods not commercially available.

- An optimal EM antenna system suitable for dig-face conductivity scanning has been designed and tested on a gantry under simulated dig-face conditions. All testing was performed using laboratory instrumentation.

Results of these activities are documented in reports summarized in Appendix A.

\section{Technology Transfer}

The TMG testing and mobile deployment will result in a proven concept that is ready for technology transfer. Vendors supplying the base instrumentation and equipment for the TMG, firms involved in buried waste cleanup, companies interested in locating buried objects (such as mining interests and oil companies), and U.S. Department of Defense contractors locating buried unexploded ordnance provide some of the markets and interest in this concept. In addition to DOE, the U.S. Navy and U.S. Geological Survey have participated in the project. The implementation and interaction of the data display hardware and software is of interest to both instrumentation manufacturers and software programmers. Disclosure of this research through professional journals and presentations at technical conferences will enhance transfer of this technology to a wider network of private sector contractors.

\subsubsection{Electrothermal Hollow Cathode Discharge Spectrometry-CH121201}

Highly selective determinations of actinides and RCRA metals can be made for characterization and monitoring of environmental action levels by combining the diode laser-based absorption, fluorescence, and optogalvanic nethod used at Ames Laboratory with furnace atomization nonthermal excitation spectrometric (FANES) systems. FANES is a versatile technique for elemental analysis and, when combined with diode laser-based optical spectrometric techniques, it can be used for isotopic analysis of actinides.

This technology provides highly sensitive qualitative measurements of samples of hazardous contamination. It can be mobilized in an onsite laboratory to provide rapid response times. The instrumentation being developed is sufficiently compact to be housed in a site-based laboratory. The technique requires minimal sample sizes and is relatively rapid (minutes for an analysis). Minimum detectable quantities are in the program regime.

\section{Accomplishments}

- The Diode Laser-Based Spectrometries FANES instrument was assembled. 
- Solid slurry sampling was demonstrated for determining lead, a RCRA metal in a river sediment sample, demonstrating useful analytical results can be obtained without time-consuming sample preparation digestion procedures that could possible cause sample contamination, and the amount of material necessary for analysis is within DOE as low as reasonably achievable (ALARA) guidelines $(<1 \mathrm{~g})$.

Three modes of signal collection were also demonstrated:

- Plasma atomic emission with a solid state photodiode array detector was shown to have food simultaneous multielement and multiline detection capabilities. These signals are used to quantitate regulated metals, and monitor matrix elements and total lanthanide and actinide concentrations.

- Diode laser absorption was demonstrated in the FANES source.

- Diode laser fluorescence measurements were made simultaneously with absorption measurements.

\section{Technology Transfer}

This system could be used during retrieval actions to verify presence of hazardous materials and actinides in soils prior to return of the treated soils. Disclosure of this research through professional journals and presentations at technical conferences will ensure transfer of this technology to private sector contractors that may be performing waste site remediations.

\subsubsection{Nonintrusive Characterization Studies-1D121112}

This task was initiated in FY-93 and will be completed in FY-95. The objective of this task is to perform a multidisciplinary assessment of commercially available instruments and sensors [magnetic, frequency domain electromagnetics (FDEM), time domain electromagnetics (TDEM), and ground-penetrating radar (GPR)] and collecting high-density data of the INEL cold test pit and publish a final report on the dielectric properties and attenuations as a function of radar wave frequency. The successful integration of data sets procured through this task will lead to a better understanding of how geophysical methods can be applied to the characterization of buried waste sites.

\section{Accomplishments}

- Multiple surveys were conducted of the INEL cold test pit. Advanced techniques were used to fuse the results from each of the individual data sets into a coherent interpretation of the targets at the pit.

- The FDEM and TDEM performed the best. The GPR system was not effective in the clay soil at the cold test pit. Data fusion techniques were limited, because favorable results occurred only with the electromagnetic sensors. However, the results reinforced the importance of using multiple sensors in a site survey for characterization. 
Information obtained through these studies is documented in the reports listed in Appendix A.

\section{Technology Transfer}

This research was conducted by Coleman Research Corporation through a Program Research Development Agreement.

\subsubsection{Field Demonstration of Characterization Technologies $-1 D 121213$}

The focus of this task is the continuation of work initiated in FY-92 by Techniscan, Inc., to evaluate advanced ground-penetrating radar (GPR) imaging methods using inverse scattering techniques. Inverse scattering is an imaging method for computing quantitative images of the physical properties of bodies by adjusting a model of those physical properties so the predicted scattered field from this body matches most closely the measured scattered field. The unique advantages of this technique compared with other more conventional approaches are:

(a) high-spacial resolution, (b) self-focusing, (c) reverberation of free images, and (d) quantitative images of dielectric constants.

The main objective of this task was to demonstrate imaging of buried objects in INEL soil with the three-dimensional scanner developed by TechniScan. The three-dimensional scanner is an inverse scattering GPR system producing quantitative, distortionless images analogous to a computer-automated tomography (CAT) system. It is intended to generate images of objects in INEL soil.

\section{Accomplishments}

During FY-93 and FY-94, Techniscan, Inc. performed a series of laboratory inverse scattering experiments to produce images of known objects in air and in high-purity sand and INEL soil. Based on those experiments, Techniscan, Inc., has developed a "body of knowledge" for future research activities including:

- The degree of image quality is directly related to the degree of accuracy in modeling electromagnetic fields of the antennas

- General methods for calibrating antennas

- A procedure for calibrating ridged horn antennas

- A theory for using soil coupled antennas for improving imaging.

Results of these activities are documented in the reports summarized in Appendix A.

\section{Technology Transfer}

A successful demonstration of this technology will enable TechniScan to market the system throughout the DOE system and in the larger waste field, including Superfund buried waste 
characterization and remediation projects. Companies interested in locating buried objects, such as mining interests and oil companies, and Department of Defense contractors locating buried unexploded ordnance, also might use the technology.

\subsubsection{BWID Dig-Face Characterization-ID132003}

This task is a continuation of work initiated in FY-93. The Dig-Face Characterization project is an integrated demonstration of multiple sensors that can be used as part of a retrieval effort. The dig-face characterization technology will allow continuous and continually improving monitoring and characterization of the site being remediated. The dig-face characterization technique is integrated into the remediation process itself. As retrieval progresses, sensor data interpretation skills improve by comparing interpreted data images with the retrieved targets.

The key objectives of this task are:

1. Demonstration of real-time data interpretation

This subtask utilizes a detailed evaluation of FY-93 data in order to provide the basis for design of a real-time data interpretation scheme. The proposed scheme will be evaluated for implementability. Prototype sensors developed in FY-93 will be evaluated for inclusion in an integrated sensor package to be tested in FY-94. A test trench will be prepared for testing the data interpretation system on realistically complex targets that are based upon representative buried waste situations.

\section{Deployment Testing}

The FY-94 approach for gantry crane testing was based on evaluation of operational features needed at the dig face and built on FY-93 progress. Measurements using magnetic and electromagnetic metal detectors were performed during a focused effort to characterize the source and amount of interference caused by the gantry crane structure and other cultural features near the crane.

\section{Accomplishments}

- Initial laboratory data have been obtained for the dielectric permitivity and gamma spectrometer sensors. Data indicate both sensors are feasible candidates for dig-face application.

- Testing is in progress for automated deployment of dig-face sensors using a robotic gantry crane system. This pilot-scale system uses a soil box to simulate the dig face and identify control system issues and needs.

- Field testing at the INEL cold test pit was completed. The system's multiple sensors are deployed with a manual nonmetallic gantry designed and constructed to complement the collection of data sets in a noninterfering environment. Data were obtained for several commercial sensors (magnetometer, electromagnetic sensor, chemical sensor) deployed over simulated targets in multiple passes as soil layers are 
progressively removed. The data will be used to evaluate resolution capabilities of the sensors.

- Volatile organic compound (VOC) sensor system design was completed.

Test results are documented in the reports summarized in Appendix A.

\section{Technology Transfer}

The successful completion of demonstrations will result in a proven concept that is ready for technology transfer. Vendors supplying the base instrumentation and equipment for the sensors (Geonics, Ltd.), those involved in waste cleanup and working with environmentally hazardous material (Ecology International), robotic programs (Buried Waste Robotics Program), and mining interests (Colorado School of Mines and U.S. Geological Survey) have participated in the project. Individual sensors as well as combined systems (sensors and robotic arm) have commercial potential in manufacturing, mining, and waste cleanup operations. Implementation of the data display hardware and software will provide private industry and other DOE partners (Sandia National Laboratories, Mound Laboratory) with an easily adaptable system to specific site requirements. Disclosure of this research through professional journals and presentations at technical conferences will ensure transfer of this technology to private-sector contractors that may be performing waste-site remediations.

\subsubsection{Electromagnetic Imaging as Applied to Mapping and Characterization of BWID-ID132018}

Funding for this TTP was received late in FY-93. The objective of this TTP is to demonstrate the use of three complementary state-of-the-art EM processing and imaging techniques in the delineation and characterization of buried waste sites. Three methods exist for generating an image of the subsurface from transient EM field data and are in many respects complementary. One objective is to produce an image of the geoelectric structure of the INEL cold test pit by applying these three imaging techniques to the high-resolution multicomponent transient EM data that were acquired by Coleman/Blackhawk in May 1993. Another objective is to recommend an optimum set of acquisition parameters to support a system for time electromagnetics subsurface imaging of buried waste sites. This should be achieved by assessing both the acquisition methodology and imaging techniques applied over the cold test pit. In the long term, the result will be to produce a reliable three-dimensional imaging method for buried waste detection, delineation, and characterization.

\section{Accomplishments}

- EM data evaluation

- Recommendation of data acquisition parameters. 


\section{Technology Transfer}

The initial research was conducted by Coleman Research Corporation through a Program Research Development Agreement. A paper was presented at the Symposium on Application of Geophysics to Engineering and Environmental Problems.

\subsubsection{Geophysical Workshop-1D132019}

The purpose of this workshop was to be a follow-on to the workshop held in FY-93, and to bring together participants of nonintrusive characterization projects funded by BWID, DOE-OT, and others interested in BWID to engage in an information exchange. However, the scope of this project closely mirrored another DOE-OTD-funded project, GPR Consortium. Ultimately, the two projects were combined under the GPR Consortium TTP and funds transferred to the BWID Regulatory Coordination TTP.

\subsubsection{Imaging Infrared Interferometer-1D142003}

This technology will enable real-time wide-area monitoring of a waste remediation site for volatile organic contaminants. This is particularly important for worker safety and providing a means of detecting point-source emissions. The objective is to develop a variable wavelength infrared imaging system that can be used for standoff site characterization and remediation monitoring and to demonstrate the ability of the instrument to detect and quantify target VOCs under various configurations, including investigations of cluttered, unstructured backgrounds such as that found at a dig face. The key attributes of this technology are the ability to identify point sources in a standoff mode, the degree of sensitivity to those contaminants, and the ability to image and monitor a wide area in near real time.

\section{Accomplishments}

- Completed the design of the prototype imager

- Initiated construction of prototype imager.

\section{Technology Transfer}

Physical Sciences, Inc., the private partner, is the primary avenue for technology transfer and commercialization. Superfund and Department of Defense sites may also have use for the technology.

\subsubsection{Very Early Time Electromagnetics_-1D142004}

The very early time electromagnetics (VETEM) system will collect and interpret data from the shallow subsurface. This instrument will operate in the region of the EM spectrum between low-frequency EM induction and GPR frequencies. The region of operation allows the system to be used at sites where GPR has little success. In addition, the project will develop physical and numeric models to determine instrument design criteria, and test processing and interpretation algorithms. New modeling, interpretation, and imaging algorithms must be developed to account 
for both diffusion and transmission effects. The instrumentation, modeling, and interpretation are being developed as a system so that the optimal package of hardware and software is achieved.

The VETEM system, along with interpretation and imaging software, will enhance resolution of the shallow subsurface at a depth between one and ten meters. Additionally, this system will operate at sites where the physical properties of the soils make high-resolution GPR difficult at waste depths. This technology could be applied to the solution of characterizing buried waste at the INEL's RWMC and other DOE sites. Specifically, it could contribute to identifying buried objects by shape, orientation, and location.

\section{Accomplishments}

- One-dimensional numerical modeling algorithms were developed, tested, and are being used in physical analysis of the buried waste problem, interpretation of field data, and in the systems analysis devoted to instrument design. The 1-D cede, with a graphical user interface, will be transferred to industry in FY-95.

- An upgraded prototype time-domain EM instrument and the second-generation frequency-domain high-frequency sounder (HFS) were fabricated and will be field tested in early FY-95. These systems will acquire data in a tenth of the time required by first-generation instruments.

- Field data were acquired at the INEL cold test pit during FY-94. A 1-D interpretation of the HFS data gave realistic estimates of the thickness, dielectric permittivity, and electrical conductivity properties of the cap covering the cold test pit waste.

Results of these activities are documented in reports listed in Appendix A.

\section{Technology Transfer}

The opportunity exists for private-sector participation in the development stages of this effort. In addition, publications in technical journals and presentations at technical conferences will inform the private sector of the progress of the VETEM system. During the final stages of development, private companies will be solicited to commercially manufacture and use the system.

Vendors supplying the base instrumentation and equipment for EM, firms involved in buried waste cleanup, companies interested in locating buried objects (such as mining interests and oil companies), and Department of Defense contractors locating buried unexploded ordnance provide some of the markets and interest in this technology.

\subsubsection{Virtual Environment Generation of Buried Waste-1D142005}

Simulation-based planning and design (SBPD) is the concept of applying computer simulation tools to the engineering process. A full-featured SBPD incorporates intelligent, integrated, automated, real-time control of the design process. Advanced visualization and computing, including virtual reality, multimedia techniques, and parallel processing, must be 
effectively implemented into the design and analysis process. Using site characterization data, physics-based modeling allows virtual prototyping.

The use of site characterization data to support advanced visualization and generation of virtual environments will play key support roles in SBPD systems. Ultimately, a full-featured SBPD system will be useful for site characterization analysis and design of actual remediation efforts and systems. An SBPD will also support worker training techniques for hazardous remediation. This improved understanding will assist in developing a remediation strategy. Improved imaging and manipulation techniques will advance remediation planning, training, and operations.

\section{Accomplishments}

- Three different prototype environments were constructed at the INEL cold test pit. Included were a walk-through characterization cell, a visual data base of the characterization cell, and an example of three-dimensional data display.

- A hardware system was designed that integrated different functionality into a single overall platform. The prototype system has access to data, database information, and analysis tools of interest or use to buried waste characteristics.

- An automatic target recognition (ATR) system was evaluated for use in assisting in data interpretation of sensor data obtained during the dig-face characterization process. The ATR system performance was good for the data interpretation application. Although there were some errors in distinguishing boxes from barrels, the system was capable of distinguishing target objects from background soil.

Results of these activities are documented in reports listed in Appendix A.

\section{Technology Transfer}

The opportunity exists for private-sector involvement in the development of this technology. SBPD has applications for many engineering processes beyond buried waste remediation, such as various mining and manufacturing concerns. Research results will be published through professional journals and presented at technical conferences. The available markets for SBPD and its application to an actual buried waste site (INEL cold test pit) should encourage private-sector contractors to improve, manufacture, and use this system for performing waste site remediations and other applications.

\subsubsection{Gravity Field Measurements-ID142011}

The objective of this task is to perform measurements of the gravity field of a well-known, well-characterized site as a demonstration of the capability of this technology. Postprocessing analysis was performed to correlate the gravity and position data. A report was generated summarizing the activities. 


\section{Accomplishments}

- Technical Status and Progress Report

- Gravity Field Measurements Capability Report

- Completed Microgravity Survey.

Results of this activity are documented in reports listed in Appendix A.

\section{Technology Transfer}

This activity was performed with commercially available equipment through a collaboration with Bell Aerospace Textron.

\subsubsection{Geophysics Airborne Platforms-1D142017}

The objective of this task is to evaluate platforms used to deploy geophysical sensors during characterization surveys including the following subtasks:

- Information on the platforms will be collected. The data will include the specification of the platforms, cost, and availability. The data will be compared against anticipated characterization scenarios at DOE waste sites.

- Specifications of EM and magnetic sensors will be assessed and evaluated against each type of platform for each respective characterization scenario.

\section{Accomplishments}

- Outline of evaluation report completed. Final report will not be completed until FY-95.

\subsubsection{Ground-Penetrating Radar Research Consortium-1D142018}

The objective of this task is to evaluate existing ground-penetrating radar (GPR) technologies, including current research efforts, and recommend a research program to develop new technologies and complimentary numerical data processing methods to improve the performance of GPR systems for buried waste site characterization.

\section{Accomplishments}

- Two surveys were completed at the INEL cold test pit, the first with the U.S.

Geological Survey (USGS) GPR unit, and the second with the new Coleman Research GPR system. Both surveys were conducted at the same spatial configurations to allow for comparison of data sets.

Results of the survey will be issued in a formal report in FY-95. 


\subsubsection{High-Resolution Imaging of Buried Waste Using Radar Array-RL342002}

The objective of this task is to design, fabricate, test, and evaluate a ground-penetrating holographic (GPH) impulse radar array system to provide near real-time holographic images of buried objects. Although the system shall be designed to be deployed on either a wheeled vehicle or other waste retrieval equipment (gantry, robotic arm, etc.), this effort only will support manual deployment. Following successful performance testing in FY-94, further field tests have been scheduled for FY-95.

The GPH system consists of a 1-m linear array of tapered slot antennae, high-speed switching network, and relatively low-power impulse source operating over a large frequency band width (approximately 2.5 to $7 \mathrm{GHz}$ ). The bistatic array system is scanned above the surface, gathers the subsurface target data, and processes the three-dimensional holographic images. Image length is continuous as the vehicle travels across the terrain with the array mounted perpendicular to the scan direction.

This technology could be applied to site characterization for buried waste in low conductivity soils. High-resolution images of buried targets (approximately $1 \mathrm{~m}$ ) in sand at the Hanford Site, and (approximately $0.2 \mathrm{~m}$ ) in INEL soil have been generated with this technology. The objective of the GPH application will be directed toward imaging shallow buried waste at Hanford, INEL, and other sites.

The GPH system is expected to offer significant improvements with the three-dimensional volumetric imaging of buried targets using multifrequency simultaneous source/receiver holographic techniques. Lateral resolution is a factor of two greater than nonsynthetic aperture imaging techniques. The multifrequency holographic image is truly three dimensional and provides an infocus image at all depths.

\section{Accomplishments}

- Successful demonstration of a 5-GHz prototype ultrawide band GPH on specific targets in a controlled environment composed of the INEL and Hanford soils.

Results of this activity are documented in reports listed in Appendix A.

\section{Technology Transfer}

The opportunity exists for private-sector involvement in the development of technology. GPH has applications beyond buried waste remediation. Various companies interested in locating other buried objects, such as mining interests and oil companies, and Department of Defense contractors locating buried unexploded ordnance, provide some of the markets and interest in this concept. The implementation interaction of the radar hardware and software with actual DOE waste sites is of interest to both instrumentation manufacturers and software programs. Research results will be published through professional journals and presented at technical conferences. This will enhance transfer of this technology to a wider network of private-sector contractors beyond remediation and mining. 


\subsection{Waste Characterization}

\subsubsection{Improved TRU Waste Assay (CTEN) AL132012}

Funding for this TTP was received late in the fourth quarter of FY-93. Work was initiated on the design and construction of the system prototype, but the majority of the work was completed in FY-94.

The objective of this TTP is to develop a system to assay TRU/fissile contents of waste drums using both epithermal and thermal neutron interrogation to reduce inaccuracies caused by self shielding. A fully operational combined thermal/epithermal neutron (CTEN) device would be expected to perform all the functions of existing differential dieaway technique (DDT) passive-active neutron devices with the added capability of identifying and assaying lumps of material.

Major tasks included in this TTP are:

- Complete Monte Carlo studies

- Complete all design drawings

- Complete fabrication

- $\quad$ Complete system software (scheduled for FY-95).

This technology minimizes the effects of self-shielding by lumps of fissile material to provide more accurate and repeatable assay of waste drums. This system will support the assay requirements of the retrieve and treat remediation option for buried waste. Specifically, it will apply to assay of intact packages of retrieved waste prior to interim storage or treatment an post-treatment assay of final packaged wastes.

Accomplishments

- Fabrication of the CTEN instrument was completed.

\section{Technology Transfer}

Though primary applications are in the waste field, use by fuel fabricator, international safeguard agencies, and Department of Defense special nuclear material monitoring may result in additional partners and deployment, or markets. A CRADA is being worked with a commercial entity to support software development. The research will be disclosed through professional journals and presentations at technical conferences to assist transfer of this technology to both private sector, contractors, and other government agencies. 


\subsubsection{Radiological and Hazardous Materials Measurement System-1D121212}

The focus of this TTP was the continuation of work initiated in FY-93. The main objective of this Radiological and Hazardous Materials Measurement System (RHMMS) is to enhance waste assay capability through improved individual measurement capability and integrating results together. Specific objectives include:

- Improve sensitivity and accuracy for gamma assay, active neutron, and thermal neutron capture measurements

- Develop methods for integrating individual measurements for improved quantitative assays.

The emphasis of the RHMMS has expanded so that individual measurement techniques being developed at different laboratories (CTEN at LANL, A\&PCT at LLNL, and DRCT at INEL) can be integrated with RHMMS to provide a complete multiple measurement system. By combining the information from all the measurements, the accuracy and confidence in the estimates of the RHMMS is greatly enhanced over that provided by individual measurements.

The RHMMS technology directly applies to remediation of buried waste sites when the waste is containerized. Additionally, retrieved waste could be assayed and packaged to ship to an interim storage or treatment facility. Prior to treatment, another assay would likely be performed, and at post-treatment an assay would be performed. RHMMS technology can perform those assays. RHMMS would certify Department of Transportation shipping limitations and various treatment facilities Waste Acceptance Criteria (WAC).

\section{Accomplishments}

- A measurement laboratory dedicated to the RHMMS concept was established at Idaho State University

- Computer modeling experiments were performed

- A proton linear accelerator based neutron generator was installed at the Particle Beam Laboratory at Idaho State University.

Results of these activities are documented in reports summarized in Appendix A.

\section{Technology Transfer}

Several expressions of interest from industry with regard to Cooperative Research and Development Agreements (CRADAs) are being evaluated. The completed system is planned for implementation by the INEL Waste Management Program. Disclosure of this research through professional journals and presentations at technical conferences will ensure transfer of this technology to private sector contractors who may be performing waste site remediations. 


\subsubsection{Hazardous and Chemical Waste Separation at RWMC Excavation Sites-1D132021}

Funding for this TTP was received late in the fourth quarter of FY-93. System components were purchased in FY-94, however, system adaptation, assembly, and testing was not completed. The project was closed due to programmatic redirection. The components were incorporated by other BWID funded projects.

\subsubsection{Excavated Waste Assay-ID142015}

The objective of this task is to develop an assay system to determine transuranic content of retrieved buried wastes or treated wastes in large volumes with relatively flat geometries (box or conveyor) based on passive gamma ray screening and spectroscopy. In addition, this project will investigate a neutron activation method for measuring the heavy metal and other hazardous chemicals and radiological components of the waste forms. The purpose of this technology is to evaluate the content of soils, especially overburdens and treated wastes, for TRU hazardous content. This technology will allow for segregation of the waste into various waste streams for appropriate treatment and disposal, both at the input and output of a waste treatment facility.

The system measurements will be made by four subsystems designed to optimize quantification and throughput. A real time radiograph determines an average attenuation coefficient. A very high-sensitivity, gross count gamma scanner determines gamma activity. A high-energy resolution gamma ray spectroscopy system identifies and quantifies Transuranics. A neutron source for activation of hazardous metal enables detection and quantification. The detector for these activated metals is the gamma spectrometer.

Accomplishments

- The algorithms developed for distance correction in the opposed detector geometry is being coded into the analysis algorithm

- The close response algorithm is being worked both with calculated methods and with experimental methods.

Test results are documented in reports listed in Appendix A.

\section{Technology Transfer}

This technology is planned for implementation by INEL Environmental Restoration. Opportunities exist for private sector involvement in both development and commercialization of this technology. Hazardous metal applications include Superfund site and mining waste processing and emissions control. Other nuclear institutions that may aid in further research or be interested in testing systems particularly for their waste stream monitoring are nuclear power plants, DOE sites, isotopic production labs, and medical establishments. Disclosure of this research through professional journals and presentations at technical conferences will enhance opportunities for transfer of this technology to the private sector. 


\subsubsection{High-Speed Digital Radiography and Computed Tomography of Waste Drums- ID142016}

Funding for this TTP was received late in the fourth quarter of FY-93. Work was developed and initiated in FY-93, however, the majority of the work was not completed until FY-94.

The work described in this TTP investigates the potential capabilities and applications of a commercial x-ray scanner for digital radiography (DR) and transmission computed tomography (CT) of waste packages, with emphasis on drums. A used, commercial DRCT scanner (circa 1987) has been acquired through government excess. The scanner uses X-rays to measure density and nondestructively view the contents of waste drums. High throughput will be evaluated by investigating an area-type detector versus a linear array. A high-energy $\mathrm{x}$-ray source could be installed for interrogation of high-density drums and will be evaluated.

The objectives of this TTP are:

- X-ray scanning system optimized and demonstrated for drum assay

- A test and evaluation report describing the capabilities of the particular system under development at the INEL and potential applications for industrial $x$-ray systems for high-speed DR and CT in waste characterization

- A report describing how DR and CT data contribute to an integrated multiple measurement system for waste characterization.

The DRCT will directly apply to the remediation of buried waste sites when the option of retrieve and treat is implemented. Retrieved, intact, containers and containers filled with retrieved wastes will be characterized and packaged prior to shipment to either an interim storage or treatment facility. Part of the assay process would be the use of DRCT to spatially characterize the package contents. This technology will support visual drum inspection like the present real-time radiography in use at certification facilities but with greater accuracy and speed.

\section{Accomplishments}

- The x-ray scanner refurbishment was completed and installed at Idaho State University.

- The new area detector was completed and prepared for testing. The system is planned to be moved to a new facility at the INEL to pursue advance testing on real waste drums currently stored at the Stored Waste Examination Pilot Plant (SWEPP).

Test results are documented in reports summarized in Appendix A.

\section{Technology Transfer}

Technology development and demonstration activities are being conducted with both government (INEL) and private sector (Scientific Measurement Systems, Inc.) involvement. 
Industry involvement in the development and demonstration phases will enhance commercial applicability of this scanner.

\subsubsection{Nondestructive Assay/Nondestructive Examination of Low Level Waste Drums-SF221209}

Work was initiated on this project in FY-92, however, full FY-93 funding was not received until the fourth quarter of FY-93. The majority of the work for this project was completed in FY-94.

The objective of this TTP is to evaluate an active and passive computed tomography (A\&P CT) system on LLW and TRU waste contained in 55-gal drums. The A\&P CT uses a high-purity germanium (HPGe) detector for nondestructive assay of gamma-emitting nuclides in sludge, combustibles, and metal matrices within a 55-gal drum. Assay is necessary for determining radiological content for below regulatory concern, LLW, and TRU waste disposition of stored wastes pre-assay and post-assay of retrieved treated waste and residues; meeting shipping requirements; and meeting RCRA low-level mixed waste disposal regulations.

The measurement of fissile elements such as U-235 and PU-239 is the most critical feature of the system. The system must optimize four critical features: spatial resolution, energy resolution, contrast sensitivity, and total data acquisition time. These parameters are governed by optimum transmission source strengths as a function of density, proper transmission source, proper detector collimation sizes and lengths, and proper balancing of waste assay speed, accuracy, and cost.

\section{Accomplishments}

The A\&P CT scanner has been developed to the state of system checkout and performance optimization. Test results are documented in reports listed in Appendix A.

\section{Technology Transfer}

Technology transfer is under way with the private partner, Bio-Imaging Research, through development of Waste Inspection Tomography (WIT) and the training, use, and data interpretation at DOE sites. The University of California San Francisco Medical School has medical expertise that is helping with this development while seeking advanced applications to medical diagnostics. Demonstration at numerous DOE sites will interest a variety of private environmental and waste assaying firms. Applications in the power industry and throughout the fuel cycle, particularly in fuel fabrication, are numerous. Safeguards monitoring and international use are also possibilities.

\subsection{Retrieval}

\subsubsection{Mobile Rapid TRU Monitoring Laboratory-ID121210}

The Rapid TRU Monitoring Laboratory (RTML) is contained in two trailers, one $8 \times 24 \mathrm{ft}$ and the other $8 \times 48 \mathrm{ft}$, which can be located in a field setting. The smaller trailer houses a 
sample preparation laboratory. The larger trailer contains (a) a computer terminal that controls and displays spectral data from four alpha continuous air monitors (CAMs), (b) two Ordela large area ionization chamber alpha spectrometers, (c) one thin window gamma ray spectrometer and automatic sample changer, (d) one VAX 4000 Model 100 computer, and (e) computer terminals and two printers used to display and generate reports of analysis results.

The unit can process over 100 samples per day of soils, filters, and smears in a field setting. The lower levels of detection vary, depending on the analysis system. The large area ionization alpha spectrometer can process 33 soil samples per day at $20 \mathrm{pci} / \mathrm{g}$ (alpha). The U-L Shell X-ray system can process 79 samples per day at $50 \mathrm{pci} / \mathrm{g}$ (alpha) and $1-5 \mathrm{pci} / \mathrm{g}$ (gamma). Simultaneously, the alpha CAMs can analyze air quality continuously at $1 \mathrm{DAC}$-hour.

The RTML is appropriate for any situation where there is a major problem with contamination of TRU that requires mitigation. The RTML can quickly evaluate situations and allow rapid remediation action to be performed that will prevent a situation from growing out of control.

\section{Accomplishments}

The system was successfully demonstrated in a field setting at the cold test pit at the INEL RWMC during the summer of 1993. An upgrade to incorporate screening capability for beta emitters and advanced screening technology for alpha emitters was completed in FY-94. Results of these activities are documented in reports listed in Appendix A.

\section{Technology Transfer}

A license agreement and property loan have been negotiated with Thermo Analytical, Inc. Thermo Analytical, Inc. will be implementing this technology at the Savannah River Site in FY-95.

\subsubsection{Three-Dimensional Graphic Simulation-1D132022}

Funds for this TTP were received late in the fourth quarter of FY-93. The contract was initiated, but work and key deliverables were not completed until FY-94.

The objective of this TTP is to modify existing commercially available software packages to provide a graphical Three-Dimensional Dynamic Simulation Tool (3DDST) for BWID systems analysis. The 3DDST will illustrate the BWID characterization/retrieval/ex situ treatment configuration option and visually define the relative merits of proposed technical development activities.

Major tasks include:

- Demonstrate the capabilities of 3DDST

- Modify and conduct final demonstration. 
The 3DDST consists of an array of computer hardware and software components that have been integrated to allow development of three-dimensional graphical display presentations featuring proposed BWID telerobotic retrieval technologies. During FY-95, the 3DDST will be further enhanced. Software equipment models will have the ability to display representative material (soil) removal, performed by BWID technologies staged at a representative model of the demonstration site.

\section{Accomplishments}

- 3-D models of the containment structure, CAT 325 excavator, and RAHCO/SPAR waste conveyance system were developed and animated

- Alternative configurations and models were developed to show ability to easily modify the simulations by replacing some models with other

- $\quad$ Simulations were developed for stacked and random drums, and models of the CAT Integrated Transfer Container can be used to replace the RAHCO/SPAR waste conveyance system.

\section{Technology Transfer}

Commercial participants for software and hardware will be identified and obtained in the first phase of this effort. It is envisioned that the demonstrated prototype system will foster the optimization of this approach. This action will ensure the availability of this system to the ER/WM elements at all applicable DOE sites as well as other complex hazardous waste sites.

\subsubsection{Real-Time Monitoring of Transuranic Dust-ID142002}

A real-time dust monitor (RTDM) will monitor for TRU-contaminated dust based on laser-induced breakdown spectroscopy (LIBS) technology. The RTDM will be correlated with an alpha CAM system. An instrument will ultimately be developed for deployment at the field environment.

The real-time monitoring aspects of this system will allow a potential contamination problem to be recognized as it develops, rather than after the fact. The RTDM can be coupled with a $\mathrm{CAM}$, giving complementary information to CAM measurements for accurate alpha determination such as particle density. It also uses LIBS strength for detection of many hazardous heavy metals that have strong emission in the visible and ultraviolet regions. At this time, analyses of potential airborne contamination are typically performed by collecting particles over time in a filter and subsequently estimating particle density offline. Depending on the level of accuracy required, this process requires several minutes to half an hour. If the particle density is subject to rapid fluctuations, offline monitoring may be inadequate. The proposed system's ability to perform real-time detection is a significant advantage in some applications.

Objectives of this task are:

- Develop system specifications 
- Complete prototype system design

- Laboratory testing.

\section{Accomplishments}

The independent safety review for glove-box testing of Pu-contaminated dust was completed. The test fixture/glove box and test instrumentation was shipped to the INEL Test Reactor Area and the Pu-contaminated dust samples were prepared.

Results of project activities are documented in reports listed in Appendix A.

\section{Technology Transfer}

The primary private customers for this technology are commercial nuclear reactors during decommissioning and decontamination phases of operation. However, the technology may also be applicable at any construction or decommissioning site where contaminated dust poses a potential health or environmental threat. Disclosure of this research through professional journals and presentations at technical conferences will enhance opportunities for transfer of this technology for commercialization. In addition, an opportunity presently exists for a government/industry partnership to promote the development and marketability of this technology.

\subsubsection{Waste Conveyance for Buried Waste and Retrieval End Effector-ID142006/ID142007}

The objective of this project is to develop a remotely controlled conveyance system to allow transfer of just retrieved waste from the dig face to the processing and/or packaging area. The project will demonstrate an integrated waste conveyance system that will reduce dust and contamination spread during conveyance of waste from the dig face to a remote packaging/transportation area. This conveyance system will be integrated with the innovative end effector used for digging and dumping.

The conveyance system will consist of an automatically guided vehicle (AGV) or gantry crane mounted device to transport retrieved buried waste. The AGV or gantry crane will be made and tested to remotely convey a variety of waste from the retrieval area to the processing or packaging area. It should be designed to transverse a variety of terrains, to operate in a hazardous environment, and to be easily maintained and decontaminated.

The end effectors consist of detachable buckets, specialized excavator buckets, integral dumping apparatus, or any other mechanism that might facilitate dust-free transfer and dumping of waste. A formal evaluation of forklift/dumpster concepts, gantry crane, and AGV designs will lead to procurement or fabrication of apparatus and conveyance mechanisms to be tested.

Technology attributes of the advance conveyance system are:

- Minimizes contamination spread during waste remediation 
- $\quad$ Minimizes personnel exposure and health risks

- Maximizes waste retrieval and transfer rates

- Verifies sampling and verification monitoring

- Assists CERCLA and Pit 9 retrieval option assessment

- Examines low dust dumping techniques in a cold environment on an engineering scale.

\section{Accomplishments}

Test alternatives for digging and dumping retrieved buried transuranic waste were determined. Dumping improvements such as sealing the dumpster to the bucket prior to dumping were tested for elimination of the soil/waste matrix falling through a distance and displacing a large volume of air. An alternative digging end effector or a detachable excavator bucket to avoid dumping in the retrieval area was tested. Testing involved putting the bucket/dumpster and AGV through a typical set of digging and dumping operations on containers spiked with rare-earth tracers.

Results of these activities are documented in reports summarized in Appendix A.

\section{Technology Transfer}

The concept and design of the system were developed by RAHCO International in conjunction with SPAR Aerospace and RSI Research. Patents are being pursued for various designs by these companies. Disclosure of this research through professional journals and presentations at technical conferences will enhance opportunities for this type of technology to be further developed by private sector industries.

\subsubsection{Remote Retrieval Demonstration-1D142008}

The buried waste program has centered investigation of the excavation of waste on three primary system components: a remotely operated excavator, an autonomous waste conveyance vehicle, and a telerobotic gantry crane. The telerobotic gantry crane is equipped with two manipulators attached to independent trolleys to deploy other technology for characterizing waste, controlling dust and contamination spread, cutting large objects, and performing archaeological excavations.

Conceptual design of a Human Engineered Control Station (HECS) was completed to provide controls and displays for the retrieval equipment. The design addressed controls, displays, work space, work arrangement, and work environment.

The HECS includes a Supervisory Control System (SCS) to aid in collision avoidance and allow for data transfer between the systems. The SCS provides a broadband data highway with network capacity to carry all data between the control trailer and retrieval enclosure. The 
network makes data from each system available for use by other systems that require the information.

\section{Accomplishments}

A Caterpillar 325L excavator was fitted with a commercially available open loop control system modification package to allow simple operations to be performed remotely. Functional and operational requirements for the SCS were developed. Results of these activities are documented in reports summarized in Appendix A.

\section{Technology Transfer}

Much of the technology development performed as part of this activity was done by industry. The Department of Defense has funded Wright Laboratories, based at Tyndall Air Force Base, to perform research and development on remote excavators. The buried waste program teamed with Wright Laboratories to leverage government funding in this development effort. Caterpillar was involved in specially fitting equipment to allow simple operations to be performed remotely. Testing was done at Jefferson Proving Grounds, a Department of Defense facility.

\subsubsection{Cooperative Telerobotic Retrieval-1D142009}

The purpose of this project is to design a system for selective retrieval achieved by multiple manipulator capability and expansion of the existing control system to achieve the necessary axes of control. Three subtasks were explored to meet this objective: design and fabrication of a remotely operated vacuum system; expansion of the control system to allow cooperative control of dual manipulators; and development of a system to deliver the retrieval equipment to the dig face.

\section{Accomplishments}

Performance tests of the gantry crane were completed, and the crane was delivered to the Robotic Center in Idaho Falls. Construction of the gantry crane footings and rails was completed. System software was developed, and verification testing was performed. Results of this research can be found in reports summarized in Appendix A.

\section{Technology Transfer}

Industry participation is anticipated in the development of a delivery system to be used in this project. Advances made in the expansion of a control system will be transferred to the control system manufacturer partnered in these activities. Capabilities developed at Oak Ridge in the area of coordinated, dual manipulation will be used in the current development efforts.

\subsubsection{Cryogenic Cutting System-1D142019}

The system uses high-pressure liquid nitrogen and solid carbon dioxide to perform cutting and abrading without the introduction of a secondary waste stream due to cutting media. The effort is focused on deploying an adaptation of the highly effective water jet techniques used in cutting and surface abrading. This adaptation removes the secondary waste stream, which makes 
water jet cutting an undesirable option for most waste management and environmental restoration activities. The cryogenic cutting technology will enhance existing fluid systems to deliver high-pressure liquid nitrogen and solid carbon dioxide to a sophisticated nozzle. The system will be evaluated by cutting select materials.

\section{Accomplishments}

During FY-94, the existing Cryogenic Cutting System underwent extensive upgrades to improve cutting effectiveness. The nozzle was attached to a gantry crane to allow it to be operated in an $18 \times 18 \times 18$ in. volume, which allowed sufficient movement to establish cutting rates with various materials. A plywood box was opened in 15 minutes at a scan rate of 0.5 in./s. A steel drum was opened by directing the jet around the periphery of the drum. For one revolution, the travel speed was 0.012 in., giving a 0.007 in. depth of cut. At this rate, eight passes were required to perforate the drum wall which would take approximately 7 hours. Results of this research can be found in reports summarized in Appendix A.

\section{Technology Transfer}

Several companies have expressed interest in collaborating in the development of this technology. Technology transfer mechanisms will be used to form the desired partnerships. Interested parties represent cutting service companies, high-pressure pump companies, control system companies, and cryogenic companies. Cryogenic cutting may have wide applicability to site decommissioning where secondary waste streams are of concern.

\subsubsection{Machine Health Monitoring-1D142020}

This monitoring system will provide remote operators with information on the status of their equipment. Information such as estimated time to failure and an overall "health of systems" index will be based on sensor and computer algorithm technology. The system will not be just informational, but will use data to limit the operator actions that could cause damage and provide emergency override mechanisms.

Selected parameters of hydraulic, electrical, thermal, mechanical, and other functions of field retrieval equipment will be monitored with appropriately designed sensors. The remote sensor capability demonstrated in the remote area vehicle and excavator with interface to computers will be extended particularly in obtaining failure mode data. Sensors available will be linked to developed algorithms contained in software modules. New sensors may have to be developed. The algorithms will analyze trend data in real time to determine failure prediction data on specified BWID equipment.

\section{Accomplishments}

During FY-94, two hydraulic test benches were fabricated to monitor real-time operating parameters including: flow rates, inlet and outlet pressures and temperatures, and vibrations. Operational and failure data were collected for four different failure modes on a fixed displacement gear pump. Based on the data collected, a failure algorithm development was initiated. Results of these activities are documented in reports summarized in Appendix A. 


\section{Technology Transfer}

The database of failure modes, the interface between sensors and computer software including artificial intelligence, and the application to actual retrieval equipment will have numerous public and private applications. Throughout the DOE complex, all remote operations, including remote retrieval, decontamination and decommissioning, and nuclear fuel cycle systems, would find the technology useful. Outside DOE, Superfund retrieval, Department of Defense ordnance remediation, mining, and special hazardous production activities are a few of the applications. Private sector involvement is being sought for CRADA participants.

\subsubsection{Remote Excavation Demonstration at Oak Ridge-_OR142003}

The objective of this task is to demonstrate a remotely operated device for retrieving waste stored in concrete casks at the Hill Cut Test Facility at Oak Ridge. The primary demonstration objectives are to demonstrate the Remote Excavation System's (RES) applicability for retrieval of this specific waste type and quantify reduction in operator radiation exposure risks. This task shall provide a hot test bed to facilitate resolving issues in support of commercialization of the remote excavation control technology.

A standard military vehicle, the Small Emplacement Excavator, was modified by Oak Ridge for remote operation and computer-assisted control. The excavator boasts automated dig and dump functions, multiple video cameras, joint encoders, and other sensor feedback. Video and control data are transmitted to the control station via radio frequency links or fiber optics. A joystick controller and a graphical computer interface were developed to provide a remote control station that is easy to use and does not require line-of-sight operation.

\section{Accomplishments}

- Cold testing was completed of the newly developed remote grappling end effector for waste cask retrieval. Cold tests included remote overburden removal, remote residual dirt clearing, and remote cask retrieval.

- Technology development preparations for the hot demonstration at the Oak Ridge Hill Cut Test Facility were completed.

\section{Technology Transfer}

Disclosure of this research through professional journals and presentations at technical conferences will promote transfer of this technology to private-sector contractors that may be performing waste site remediations. Many companies have expressed interest in the control technology and operator interface technology, and several are pursuing CRADAs. Mechanisms will be sought to transfer the technology to interested parties. 


\subsubsection{Contaminated Material Excavation, Handling and Retrieval System-RL342001}

The objective of this task is to develop a conceptual design of a containment facility to remotely retrieve, package, and handle contaminated waste. The conceptual design will be oriented toward a prototype facility that may be used for a field demonstration of the retrieval, packaging, and handling system in a buried waste environment for hot-spot retrieval. Engineering conceptual design requirements for the containment facility will be prepared by the investigator and submitted to the BWID program for technical review.

\section{Accomplishments}

The draft engineering study and conceptual design were completed. Results of this research can be found in the reports summarized in Appendix A.

Technology Transfer

Disclosure of this research through professional journals and presentations at technical conferences will promote transfer of this technology to private-sector contractors that may be performing waste remediations.

\subsection{Containment/Stabilization}

\subsubsection{In Situ Vitrification-ID111202}

The objective of this task was to get an operational ISV Lab Test Facility at the INEL and to resolve technical issues related to ISV remediation of transuranic pits and trenches located at the INEL. All technical work was completed on this project during FY-92 and FY-93. FY-94 activities included two presentations at a technical conference and completion of the final ISV Test Series 1 results and TOUGH code modeling reports summarized in Appendix A.

\subsubsection{In Situ Encapsulation of Buried Waste-1D142012}

In situ grouping involves the injection of calcium carbonate precipitating solutions into buried waste streams, encapsulating them in a carbonate cemented block that is impervious to water migration. The technique can also be used as an intermediate stage to solidify waste to prevent future aerosolization of contaminants should retrieval be necessary.

The concept is an analogue of the natural processes that produce classic sedimentary rocks. Loose unconsolidated soil or sediment is converted into a hard, durable, impermeable rock by precipitation of minerals (cement) from groundwater between the particles of unconsolidated materials. The most common natural cements are calcite $\left(\mathrm{CACO}_{3}\right)$, hematite $\left(\mathrm{FE} 2 \mathrm{O}_{3}\right)$, and various forms of quartz $\left(\mathrm{SiO}_{2}\right)$. The existence of such rock in the natural environment for long periods requires that they be in chemical equilibrium with their surroundings. The success of using artificial analogues of natural cementing processes to encapsulate and isolate waste materials hinges on the ability of the aqueous cementing solutions to penetrate and permeate INEL soils. 


\section{Accomplishments}

Laboratory-scale tests were conducted at the INEL using synthetic analogs of natural cementing agents to determine if the iron oxide material (hematite) was suitable for a waste encapsulation material for application at the INEL Subsurface Disposal Area. The data indicate that the iron oxide waste encapsulation materials tested are appropriate choices for mixing with INEL soil to encapsulate waste. Field tests were recommended to determine the performance of the material under field conditions of pumped grouping monitoring over an extended period.

Details of this research can be found in reports summarized in Appendix A.

\section{Technology Transfer}

The technology participants from the INEL and private vendors aid in technology transfer. Additional industrial and university participants will be involved in the program as requirements and needs become better defined. The data obtained from each of the activities will allow technical evaluation for remediation by private, DOE, and Environmental Management concerns.

\subsubsection{Innovative Grout Demonstration-1D142014}

The objective of this task is to demonstrate an innovative grouting/retrieval concept for application in buried transuranic waste sites. This concept provides both containment and retrieval contamination control by reducing the spread of dust during retrieval.

The innovative grouting/retrieval technology involves three operations: grouping, fracturing, and retrieval. The first step is to grout the waste and surrounding soil, causing an agglomeration of fine soil particles that may have become contaminated. Buried waste is jet grouted at high pressure $(6,000 \mathrm{psi})$. After curing, the monolith (grouted block) can be left in place as interim storage for up to 20 years, or it can be fractured for subsequent removal. Once the fracturing occurs, the fractured block of grouted waste are removed and packaged for permanent disposal.

\section{Accomplishments}

During FY-95 the jet grouting retrieval technique was demonstrated in a cold simulated test pit with a positive proof of principle. A solid monolithic block was created, and a standard backhoe removed chunks after fracturing.

Details of this research can be found in reports summarized in Appendix A.

\section{Technology Transfer}

This concept could be transferred to the INEL Environmental Restoration Program for use by the private sector for remediating transuranic pits and trenches. The private sector could also use this technique on buried waste sites where contaminant spread is a problem. 


\subsubsection{Monolithic Confinement-RL421212}

This project was coordinated by a team from Westinghouse Hanford and the INEL. Monolithic confinement is a method to create a barrier to water movement in fractured rock underlying buried waste by cementing the cracks of the rock underground. The process also immobilizes contaminants in the waste or underlying rock.

A special purpose oil field/mineral type drill (Casa Grande drill apparatus in this case) drills into basalt formations such as that at the INEL. Grout (Portland cement) is pumped under $6,000 \mathrm{psi}$ pressure through a rotating orifice as the drill is retracted. The grout fills the inner granular cracks in the basalt while simultaneously locking contaminants that may have spread to regions below buried waste.

The in situ process is a low-impact strategy for buried waste confinement compared to more intrusive remediation techniques. There is minimum disturbance to the waste, and risk of surface contamination is reduced. The grout can also be injected into the waste as the drill bit is retracted, further reducing waste permeability to water and subsidence.

\section{Accomplishments}

Monolithic confinement was successfully tested at a test area near the INEL possessing a geologic configuration similar to that found at the INEL. Reduction of hydraulic conductivity of one to two orders of magnitude was demonstrated in the fractured basalt matrix. Grout penetrated up to $4 \mathrm{~m}$ from the drill hole. A tracer sensitive to ultraviolet light was used to provide positive identification of grout penetration.

Results of these activities are summarized in reports listed in Appendix A.

\section{Technology Transfer}

Personnel from Westinghouse Hanford Company are in the process of privatizing the process with a company called Applied Geotechnical Engineering and Construction Inc. The business plan is currently being reviewed. Considerable cost savings have already been demonstrated while operating for Westinghouse. The company has already received requests from various federal and state agencies, as well as inquiries from the private sector.

\subsection{Treatment}

\subsubsection{Secondary Treatment of BWID Off-Gas Using Nonthermal Plasma-AL142002}

The objective of this project is to evaluate the nonthermal plasma (NTP) process for removing VOCs, SOx/NOx, hazardous compounds, and high vapor pressure metals (HVPM) in melter off-gases.

Nonthermal electrical discharge plasmas can promote favorable chemistry for the destruction of hazardous chemicals. Electrical energy directed into the process chemistry creates highly 
reactive free radicals that oxidize or reduce pollutants, fragment pollutants directly, or promote excited-state chemistry.

Silent discharge plasmas consist of two parallel metal electrodes with a dielectric barrier covering one or both electrodes. High voltage is applied between the electrodes, creating micro-discharges in gases flowing between them. The electrical energy is channeled into free radical production. This creates an active environment for destruction of gaseous-based hazardous organics.

This technology is an alternative nonincineration treatment for volatile organic destruction and metal oxidation in remediating contaminated soil and direct mixed waste treatment. It also treats secondary waste gases from commonly used treatment processes for mixed waste such as vitrification, incineration, and thermal stripping.

NTPs have two major applications for hazardous waste treatment:

- $\quad$ Primary Stage. Treating gaseous-based wastes such as VOCs in stack gas and a stand-alone plasma devices

- Secondary Stage. Treating the off-gas stream of incompletely destroyed waste from primary stage units and incinerators or furnaces.

\section{Accomplishments}

A surrogate off-gas mixture for arc melter outputs was defined. Conceptual designs were formulated for lab-scale evaluation tests at Los Alamos and demonstration testing on a bench-scale arc melter. Lab-scale apparatus for low-temperature $\left(<300^{\circ} \mathrm{C}\right)$ testing was designed and assembled, and testing on the surrogate mixture was started. A laboratory-scale NTP system was demonstrated for the removal of various organics and HVPMs that are characteristic of a high-temperature $\left(>500^{\circ} \mathrm{C}\right)$ arc melter operated in a reducing mode. Oxidation of HVPMs and destruction of organics were assessed in various atmospheres, including those with high-particulate loadings and at various flow rates and surge conditions. Feasibility tests for HVPM vapors are progressing.

Results of these activities are summarized in the reports listed in Appendix A.

\section{Technology Transfer}

Other DOE sites such as Savannah River, Hanford and Mound, and participants in the industrial sector such as the chemical, electrical production, and paper and wood products industries support this technology. The Electric Power Research Institute intends to cooperate with DOE on an air toxic effort through a CRADA and technology commercialization with the private sector. 


\subsubsection{STRATEX-CH232002}

The objective of this project is to develop and evaluate STRATEX, an integrated system of several technologies for processing radioactive and hazardous wastes.

STRATEX is an integrated system to treat contaminated soil and other high-volume radioactive and hazardous wastes. Synergistic physical and chemical processes combine thermal desorption, steam stripping, and solidification/stabilization into an efficient treatment system. STRATEX overcomes the inherent heat transfer and turbulence problems with several features.

Instead of sequential treatment of thermally desorbing soil and solidification, STRATEX combines both steps into one operation. Compared with typical sequential treatments, STRATEX is less expensive, easier to maintain, able to handle higher volumes, able to handle a greater variety of wastes, and safer in terms of exposure and operation.

\section{Accomplishments}

A laboratory feasibility study of STRATEX evaluated and optimized the system's removal efficiency for organic contaminants, volatile metals such as mercury and arsenic, and stabilization of non volatile inorganic contaminants. Binder selection, operating parameters, and estimated costs were determined. STRATEX has been evaluated for specific DOE site soils and contaminants. Performance and cost has been estimated and compared with existing technologies.

\section{Technology Transfer}

A private independent consultant is involved as a joint participant to assist in timely technology transfer. A private environmental restoration and waste management company will become involved as a joint participant during the demonstration phase. After technical viability is demonstrated, formal CRADAs will be developed. Other Argonne, DOE, and Department of Defense sites are interested in the technology. STRATEX is a patented process giving added incentive for privatization and commercial use.

\subsubsection{Ice Electrodes-1D121211}

The objective of this project is to develop and test an ice electrode to remove heavy metals from liquid waste streams and recover valuable metals and minerals for possible resale.

An ice electrode is a conventional electroplating electrode coated with a thin sheath of ice produced by a liquid nitrogen cooled nitrogen gas flowing through an electrode. Bench-scale tests indicate that metals which can be electro-deposited on a conventional electrode can also be electro-deposited on an ice electrode. Preliminary work with metals that do not electro-deposit on conventional electrodes, such as uranium and tungsten, suggest that oxides of such metals can be recovered at an ice electrode. Metals can be recovered simply by allowing the ice to melt.

The ice electrode technology has application in any process that produces metal-bearing waste solutions, including private sector mining waste streams and metallic DOE or Department of Defense process solutions from product fabrication and cleaning. 
Ice electrodes can recover metals not possible by conventional electrodeposition, retrieve oxides of uranium and tungsten, allow easy recovery of metals with no additional chemicals, and minimize waste generation because the electrode is not destroyed due to the presence of the ice sheath.

\section{Accomplishments}

Initial proof-of-concept testing of the ice electrode bench-scale system was performed at Environmental Research and Development's facility. The reactor was able to plate copper on the ice surface.

\section{Technology Transfer}

Ice electrode technology will be useful for waste treatment and processes that deal with metal-bearing waste solutions, including private sector mining waste streams, plating companies, and metal cleaning operations. Technology gains from treatment of DOE and Department of Defense streams will transfer readily and be of great value to a variety of private concerns.

\subsubsection{BWID Waste Form Integration and Limits-ID132006}

The objective of this project is to determine the waste form compositional limits within which an acceptable waste form can be produced and have the required durability for subsequent treatment, storage, and/or disposal.

\section{Accomplishments}

A report summarizing leach resistance, mechanical durability, and recommended limits of composition was completed. A report detailing BWID standard waste and soil compositions was completed. A report on the compositional limits from which an acceptable waste form can be produced was completed. Details of these reports are summarized in Appendix A.

\subsubsection{BWID Thermal Kinetics-1D132010}

All activities associated with the project were completed in FY-93. An informal report that combines the TOUGH2 code report with the quick look report on ISV lab test series 1 , and a letter report on small-scale phenomenological experiments were completed with FY-93 carryover funds. Summaries of these reports are listed in Appendix A.

\subsubsection{BWID Arc Melter Vitrification-ID132011}

The objective of this project is to demonstrate in an operational commercial scale plasma arc melter the applicability and feasibility of existing plasma arc melter technology for high-temperature treatment of transuranic and mixed hazardous wastes and buried or stored soils.

A plasma arc furnace pyrolyses and combusts organic materials and melts residual inorganic materials with an electric arc. The American Society of Mechanical Engineers (ASME)/U.S. Bureau of Mines (USBM) plasma furnace features three carbon electrodes, cooled sidewalls for 
skull operation, continuous feed system, off-gas treatment system, and slag and metals tapping capability. Upon cooling, the resulting molten slag produces a durable vitrified cast form that may be safely disposed of.

The advantages over conventional thermal treatment processing methods include high temperatures, high enthalpies, choice of inert or chemically active torch gases, and operation with low gas volumes. The key advantage of arc melter technologies is the ability to process a wide variety of homogeneous waste into a durable glass ceramic waste form that is more leach resistant at less volume than other waste forms, such as compacted or cemented incinerator ash.

\section{Accomplishments}

The existing off-gas system components can be modified for TRU surrogates and heavy metals containment. Approximately 20 to $30 \mathrm{t}$ of simulated waste could be processed in each melt campaign, or about 4 to $6 \mathrm{t}$ per day. Surrogate wastes, including soils, metals combustibles, and sludges, were prepared and incinerated.

Research on equipment for gas handling, cleanup of secondary waste, and reducing plasma energy requirements further should reduce downstream costs. Experiments included analysis of slag and metal phases, off-gas, and off-gas system residues. The melt campaign is complete. CRADAs are being finalized and a complete interim technology evaluation report is being written.

Details of this research are summarized in the reports listed in Appendix A.

\section{Technology Transfer}

University, industry, and other laboratory participants are being solicited. Because many private sector companies are members of the present ASME test consortium, CRADAs with industrial partners are being sought to speed completion of the demonstration project and accelerate technology transfer to the private sector.

\subsubsection{Modeling of Thermal Plasma Arc Technology-1D142010}

The objective of this project is to develop a computer model of the plasma arc treatment process giving the most likely composition of final waste slag and off-gas, location of heavy metals, and size and distribution of slag and metal pool.

The computer model of the plasma arc treatment simulates a variety of plasma arc waste treatment facilities. It determines the migration of particulate and gaseous contaminants to the off-gas both by composition and into the equipment. The contaminants encapsulated within the final waste slag and the effects of molten metal pooling on the chemistry and heat transfer of the arc plasma also have been modeled. Further data needed to model the chemical aspects of the plasma arc process, but not found in the current databases and model limitations, will be provided.

The model can be used to develop, optimize, and understand plasma arc technology; reduce the operation costs of current arc melters; determine the migration of the contaminants during 
and the location of the contaminants after the process; develop designs that are more efficient (i.e., capture more waste within the vitrified product); determine areas in which experiments may most benefit the advancement of the technology; and understand the cause and effects of the physical processes occurring within the plasma arc facilities.

\section{Accomplishments}

The FIDAP code (a commercial code) to calculate heat transfer was modified and two-dimensional axis-symmetric transferred direct current (DC) arc model validated. The effects of molten metal pool on electric field and heat transfer via FIDAP and performed chemistry code simulations were calculated.

Details of these activities are summarized in the reports listed in Appendix A.

\section{Technology Transfer}

The model can be transferred for use at other public and private facilities including specific application at Pacific Northwest Laboratory (PNL), Massachusetts Institute of Technology (MIT), and USBM. The experimental work from these institutions and furnace manufacturers can aid in validating the code. The intermediate and final codes will be transferred to plasma arc developers and end users.

\subsubsection{Graphite DC Arc Plasma Furnace and Diagnostics-RL321211}

\section{Graphite DC Arc Plasma Furnace}

The objective of this task is to demonstrate and evaluate a graphite electrode, DC arc furnace for processing radioactive waste (both low-level and TRU) and mixed waste and soil.

The Mark II furnace is a refractory-lined, carbon steel vessel measuring $23 \mathrm{ft}$ high and $7 \mathrm{ft}$ in diameter, with four soft patch panels around the circumference to provide assess for waste feed, glass discharge, and diagnostic equipment. The furnace is designed for semiremote operation, alpha containment, and ability to process a $1-\mathrm{MV} \cdot \mathrm{A}$ power giving up to $1.5 \mathrm{ton} / \mathrm{h}$ processing rate.

The coaxial arrangement is unique. The outer graphite electrode is $14 \mathrm{in}$. outer diameter and $10 \mathrm{in}$. inner diameter. The inner electrode is a solid 6-in. piece of graphite. The electrode assembly can be operated in the transferred arc mode or the nontransferred arc mode (arc between parts of the electrode).

The plasma arc technology can treat any type of buried waste (hazardous, low-level, and transuranic), along with any contaminated soils and containers. Organics are destroyed and metals (both radioactive and hazardous) are stabilized in a suitable final waste form. Ash and secondary waste and soil can be treated.

The Mark II has several advantages:

- It can handle objects as large as a 35-gal drum 
- Destruction of limited quantities of hazardous materials can be tested

- The off-gas system is suitable for a full-scale production furnace

- The plasma arc can treat any type of buried waste (hazardous, low-level, and transuranic), along with any contaminated soils and containers

- The final waste form (slag, solidified residue) is extremely durable and shows similarly to log life natural analogues

- Incoming waste can be used to decrease off-gassing, thereby reducing secondary waste.

\section{Accomplishments}

An engineering-scale furnace, the Mark I, was built and demonstrated, and design improvements are ongoing, including development of improved diagnostics. Surrogate has been treated with this furnace. A large pilot-scale unit has been built, the Mark II, incorporating off-gas treatment, higher power, and throughput. The Mark II furnace was tested at higher throughputs than the Mark I using a continuous processing mode. Operation of the furnace is being evaluated from the standpoint of materials feeding, glass and metals pouring, electrode design, stability, and overall operability including off-gas.

Details of these activities are summarized in the reports listed in Appendix A.

\section{Technology Transfer}

Other commercial entities have expressed interest in both the melter and diagnostic technology. Technology transfer is occurring with MIT and industry (Electro-Pyrolysis) partners on the project. Technical progress reports and design data will be transferred to other projects, especially similar vitrification efforts.

\section{Diagnostics}

Measuring the destruction efficiency of organics, volatilization, and incorporation of metals (both radioactive and hazardous) are essential for successful stabilization and a suitable final waste form. Measuring an adjusting parameters can also minimize any secondary waste. The objective of this task is to demonstrate and evaluate innovative diagnostic tools for monitoring arc furnace treatment processes in situ in real time.

The high-temperature real-time measurement systems include analytical equipment for measurement of furnace and glass temperatures and exhaust emission in the furnace chamber and off-gas line. A millimeter wave radiometer for measuring furnace and glass temperatures is more transparent to the furnace environment than infrared pyrometers.

In situ gaseous and particulate emission measurement and analysis in real time are tested on specially deconfigured plasma sources. Molecular emission analysis and particle size and velocity determination are used to monitor composition of solid material at various processing stages. 
The in situ high-temperature monitoring and measurement system should:

- Monitor the destruction of hazardous materials

- Be durable and able to monitor the off-gas system from a full-scale production furnace

- Work on a variety of arc furnaces used to treat any type of buried waste (hazardous, low-level, and transuranic), along with any contaminated soils and containers

- Assist in determining if the final waste form (slag, solidified residue) is durable and meets specifications

- Reduce secondary waste by an improved waste form, increased processing efficiency, and decreased off-gassing.

\section{Accomplishments}

An engineering-scale furnace has been built and developed with improved diagnostics. Surrogate waste has been treated with temperature and composition monitors used. Improved diagnostics include analytical instruments to make spatially resolved measurements of furnace and glass temperatures and to measure gas concentrations both in the furnace and off-gas exhaust line. A self-calibrating millimeter wave radiometer, plasma sources, and analytical instruments have been developed. An R\&D 100 award was received for these efforts.

Molecular emission analysis, particle size and velocity determination, and composition of solid materials at various stages of processing were measured. The continuous online off-gas system was used to assist in the material balance and provide input, along with the temperature sensors to optimize the furnace design.

Details of these activities are summarized in the reports listed in Appendix A.

\section{Technology Transfer}

Other commercial entities have expressed interest in the melter diagnostic technology. Technology transfer is occurring with MIT and industry (Electro-Pyrolysis) partners on the project. Technical project reports and design data will be transferred to other projects, especially similar vitrification efforts.

\subsection{Programmatic}

\subsubsection{BWID Program Coordination-1D132008}

The objective of this TTP was to provide support for the general planning, coordination, and management for BWID implementation. The Program Office, referred to in Section 2, was created and organized to accomplish this task. The coordination effort funded by this TTP is a multifunctional support effort for DOE. Specifically, tasks included in this TTP are: 
1. The general BWID programmatic and technical planning, coordination, and management for implementation

2. Oversight to ensure individual BWID-sponsored technologies comply with all applicable environmental, safety, health, and quality requirements during field deployment demonstrations for technology testing and evaluation

3. Technical coordination to ensure programmatic objectives are maintained and planned into future activities of the BWID program.

\section{Accomplishments}

- The FY-94 BWID Program Report (DOE/ID 10454) was completed

- Two technology transfer meetings were conducted

- The BWID FY-93 Closeout Report (EGG-WTD-11136) was completed

- Program personnel presented posters and/or papers at six technical and/or DOE-sponsored conferences

- The BWID Mid-Year Technical Peer Review was conducted

- The BWID FY-95 Proposal Guidance and Needs Assessment was completed

- The BWID FY-95 proposal review and technology selection was completed

- The BWID IDC participated in the FY-94 DOE OTD Mid-Year Program Review

- Program personnel supported four program and/or focus area technical reviews

- The BWID FY-94 Technology Exhibition was conducted

- BWID Lessons Learned 1993 Technology Demonstrations (EGG-WTD-11123) was completed.

A summary of these reports are listed in Appendix A.

\subsubsection{BWID Technical and Academic Review Group-ID132015}

The objective of this TTP is to fund the activities of the BWID TARG. The purpose of TARG is to provide technical oversight and guidance to the BWID technology demonstration process.

Tasks included in this TTP are: 
- Identify and generate functional performance requirements necessary for assessing technology effectiveness

- Define the current state-of-the-art technology in each BWID functional performance area

- Identify and prioritize technology gaps, based on system functional and technical requirements

- Characterize technology gap areas that are not being addressed by current and past BWID-funded efforts

- Provide general technical oversight and support for FY-94 BWID-funded technical demonstration projects.

Accomplishments

TARG members participated in the FY-94 BWID Mid-Year Technical Peer Review and provided technical evaluation comments to PIs. TARG members participated in the FY-95 BWID proposal review and selection process. TARG members also participated in the FY-94 BWID Technology Exhibition.

Details of this activity are documented in Appendix A.

\subsubsection{BWID/EM-40 Interface-1D132023}

The objective of this TTP is to provide a vehicle for continued exchange of information between BWID and EM-40 activities to establish a baseline of current technological capabilities for evaluation of future BWID technological advancements.

Specific tasks included in this TTP are:

- Review of INEL Pit 9 Retrieve/Ex Situ Treatment remedy bid proposals

- Assessment of proposed BWID technologies relative to EM-40 remediation plans

- Continue the joint INEL EM-40 BWID systems analysis concepts

- Establish a stronger liaison with EM-40 through the BWID Program Planning Group to obtain additional site-specific EM-40 input for technology data needs.

\section{Accomplishments}

Memorandum purchase orders were place with EM-40 representatives from Oak Ridge, Hanford, and Savannah River sites to support development of technology needs and review of test plans for BWID's Program Planning Group. The Treatment Configuration Options Report (EGG-WRD-10968) was issued. Environmental Restoration (ER) representatives from Oak 
Ridge and the INEL participated in the BWID FY-94 Mid-Year Technical Program Review. The BWID Program Video was released. The video presents an overview of the BWID program, showcases past technology demonstrations, and discusses future activities relative to technology transfer and private sector involvement. ER representatives from Oak Ridge, Savannah River, and Hanford participated in the BWID FY-95 proposal review by providing written comments on the new proposals. ER representatives from Savannah River and Oak Ridge participated in the BWID Technology Exhibition.

\subsubsection{BWID Technology Deployment-ID142013}

This project provides multifunctional support to DOE. Objectives of this task are (a) oversight to ensure individual BWID-sponsored technologies comply with all applicable environmental, safety, health, and quality requirements during field deployment demonstrations for technology testing and evaluation, and (b) technical coordination to ensure programmatic objectives are maintained and planned into future activities of the BWID program.

Tasks required to meet the objectives of this project provide technical oversight and coordination of regulatory documentation for field deployable technologies, operational support to demonstration activities such as training, test facility preparation, restoration, etc., and performance reviews of field deployable technologies.

\section{Accomplishments}

- All NEPA documentation and hazard classifications for BWID technologies were completed

- A draft BWID/DOE Complex ER integrated schedule was completed

- The ESH\&Q Plan for BWID was issued

- The BWID Project Management Plan was completed

- The BWID Deployment Plan was completed

- BWID demonstration schedules were completed

- Coordination of the Box Canyon and cold test pit sites for technology demonstrations was provided.

Details of the reports issued can be found in Appendix A.

\subsubsection{BWID Technology Acceptance and Oversight-ID142022}

The objective of this task was to develop engineering fact sheets for BWID-sponsored technologies selected by the Committee to Develop Onsite Technologies (DOIT) of the Mixed Waste Working Group of the Western Governors' Association (WGA) and to investigate collaboration opportunities between BWID technology demonstrations and the U.S. 
Environmental Protection Agency (EPA) Site Program. Details of these activities are outlined in Appendix A.

\section{Accomplishments}

A representative from BWID attended the WGA DOIT Committee Implementation Workshop. BWID representatives attended several meetings sponsored by the WGA Mixed Waste Work Group resulting in the formation of the Demonstration Site Implementation Team (DSIT). DSIT has representatives from the State of Idaho, WGA, Idaho Indian Tribes, Special Interest Groups, DOE, DOE contractors, labor unions, EPA, and city governments. Technology fact sheets were drafted for the four BWID technologies selected by the DOIT Committee. A letter report was issued outlining the protocol between BWID demonstrations and the EPA Site Program. The draft report of the BWID/EM-40 Technology Transfer Protocol was completed.

\subsubsection{Technology Implementation and Public Participation-1D144101}

The objective of this TTP is to support the BWID PIs to maximize the commercial potential of the technologies being developed through the BWID program, including assessing market needs (DOE and industry), soliciting industry opinions, finding commercial contacts, and effecting public participation and stakeholder involvement through the following two subtasks:

- Technology Implementation-Assist in commercialization efforts, liaison between industry, academia, and BWID; information transfer on BWID technologies to appropriate individuals in EM-30, 40,60; serve as a regional point of contact and broker of EM services to industry; serve as local site liaison to the central point of contact and provide services to support that function; prepare and convene regional industry fairs/workshops; collect and package information on licensable EM technologies; package information on EM technologies for dissemination to industry, academia, and public groups; provide BWID needs descriptions for Headquarters procurement specialists at DOE operations office; interface with small business coordinators and procurement specialists at DOE operations office; and communicate with companies interested in licensing or providing venture capital assistance through business development and brokering efforts.

- Public Participation-Provide public participation support to BWID; continue implementation of public participation plan for BWID; complete or update the BWID public participation plan; send representatives to attend EM-50 national community leaders workshop; send BWID representatives to attend public participation planning workshops; conduct stakeholder meetings; and provide EM technology transfer network support.

Accomplishments

- $\quad$ BWID Stakeholder Involvement Model (EGG-WTD-11191) was completed

- $\quad$ Conducted a stakeholder meeting in Seattle in December 1994 
- Completed Volume 1 of the BWID Technology Commercialization Action Plans (EGG-WTD-11252)

- Completed Volume 2 of the BWID Technology Commercialization Action Plans (EGG-WTD-11252)

- Completed draft of Volume 3 of the BWID Technology Commercialization Action Plans.

The final reports are summarized in Appendix A. 


\section{FINANCIAL ASSESSMENT}

See Table 1 (page 4) for a funding summary of the FY-94 BWID program. Data for this summary were obtained from DOE's September Financial Plan and September Progress Tracking Report. Values were validated for the INEL TTPs as of December 1994. Validation of the remaining TTPs was not possible before publication of this document. 
Appendix A

\section{List of Buried Waste Integrated Demonstration \\ FY-94 Reports}





\section{Appendix A \\ List of Buried Waste Integrated Demonstration FY-94 Reports}

\section{SITE CHARACTERIZATION}

\section{TTP AL911201: Nonintrusive Sensing of Environmental Important Objects}

Chem-Nuclear Geotech, Inc. Report. Optimal Induction Electromagnetics for Dig-Face Characterization Final Report. The objective of dig-face characterization is to map physical properties immediately adjacent to the surface of an active remediation dig face. The induction electromagnetic (EM) method is a noninvasive geophysical method that is sensitive to conductive material in proximity to its antennae. This report describes and justifies the EM antenna geometry chosen for dig-face characterization and presents results of full-scale tests of the array geometry over targets that simulate those expected to be encountered during a dig-face retrieval operation. Conclusions and recommendations describe a proposed field instrument suitable for full-scale testing of dig-face characterization with EM scanning. The proposed instrument would be compatible with other sensors and, thus, could be run as one of several sensors mounted in a specially configured sensor package for dig-face characterization.

Chem-Nuclear Geotech, Inc. Report. Time Domain Electromagnetic Survey of Three Waste Pits at the INEL RWMC. September 1994. This report documents the broadband electromagnetic surveys conducted by Chem-Nuclear Geotech, Inc. The cold test pit, the Acid Pit, and Pit 9 within the Radioactive Waste Management Complex (RWMC) at the Idaho National Engineering Laboratory (INEL) were surveyed. The surveys were performed with the Geonics, Ltd., PROTEM 47 time-domain electromagnetic (TDEM) system operated in the fixed-separation, moving coil mode. Conductive zones interpreted to be boundaries of the cold test pit and Pit 9 were easily mapped with the method. The contents of the Acid Pit did not appear to respond to the TDEM method, although a small conductive area was mapped in the west central portion of this pit.

Chem-Nuclear Geotech, Inc. Report. Technical Progress Report for Electromagnetic Methods for Dig-Face Characterization. The purpose of this report is to status recent progress relating to TTP AL911201-G5 and to supplement information contained in the Technical Preparedness and Status Report submitted in November 1993.

Chem-Nuclear Geotech, Inc. Report. Technical Progress Report for Site Characterization and Object Location using Tensor Magnetic Gradiometer (TMG). The purpose of this report is to summarize the technical progress and accomplishments made during FY-93 in connection with TTP AL911201-GA (Site Characterization and Object Location using a TMG). 


\section{TTP CH121201: Electrothermal Hollow Cathode Discharge Spectrometry}

All milestone deliverables for this project have been delayed to FY-95. (Draft Test Plan, Draft Report on Actinide Analysis Tech., Draft Analytical Method Report, and Final FY-94 Report)

\section{TTP ID121112: INEL Nonintrusive Characterization and Sensing of Buried Objects}

Test Plan for Ground-Probing Radar. This test plan is a preliminary description of a testing program for ground-probing radar (GPR) at the INEL. Four experiments are recommended. Detailed specifications are provided where needed to evaluate the scope and extent of the work. Additional specifications will be required for the final test plan. Other experiments are described in broad terms and should be considered as guidance for management decisions regarding the GPR testing program at the INEL.

Final report for Ground-Probing Radar. Factors Affecting Ground-Probing Radar at the $R W M C$ at the INEL. This is the final report of a project conducted to investigate ground-probing radar (GPR) performance at the INEL. The project investigated the parameters associated with GPR performance in surface soils near the RWMC. Hazardous and radioactive wastes are buried at the RWMC Subsurface Disposal Area (SDA), and the U.S. Department of Energy (DOE) is seeking noninvasive site characterization techniques for detecting and mapping the burial pits, waste containers, and soil contaminants in the SDA.

\section{TTP ID121213: Field Demonstration of Characterization Studies}

TechniScan, Inc. Draft Test Plan. This test plan identifies those indoor laboratory tests, to be performed during FY-94, necessary to evaluate the inverse scattering algorithm developed by TechniScan, Inc. A laboratory-scale GPR system will be used to collect imaging data of simulated waste containers buried in sand and in INEL soil, with ultimate use at the RWMC to characterize buried waste. The three major testing objectives covered in the test plan are (1) calibration of a laboratory-scale scanner and associated data collection equipment using objects positioned in air, (2) using the calibrated GPR, collect inverse scattering data on simulated waste objects buried in sand, and (3) collect inverse scattering data on simulated waste objects buried in INEL soils.

TechniScan, Inc. Final Report. This report summarizes TechniScan, Inc. activities in evaluating advanced GPR imaging methods using inverse scattering (IS). IS an imaging method for computing quantitative images of the physical properties of bodies by adjusting a model of these physical properties so that the predicted scattered field from this body matches most closely the measured scattered field.

\section{TTP ID132003: BWID Dig-Face Characterization}

Draft Prototype Dielectric Permittivity Sensor Final Report. This report describes results of experiments conducted in collaboration with the U.S. Geological Survey (USGS). Data indicate that dielectric permittivity contrasts can be mapped in the presence of soil 
conductivity contrasts, since the two effects are distinguishable at different frequencies. Initial experiments with the prototype small coil system were somewhat hampered in these first experiments due to electronic interference effects. Work is in progress to solve this problem. It is also worth noting that the small coil sounder was recently used by the USGS to detect a paraffin target and plastic underground pipes at a test site in San Antonio, Texas.

EGG-WTD-11424 Test Plan for FY-94 Dig-Face Characterization Field Experiments. The dig-face characterization concept has been under development at the INEL since FY-92 through the support of the Buried Waste Integrated Demonstration Program. A dig-face characterization system conducts continuous subsurface characterization simultaneously with retrieval of hazardous and radioactive waste from buried waste sites. The system deploys multiple sensors at the retrieval operation dig face and collects data that provide a basis for detecting, locating, and classifying buried materials and hazardous conditions before they are disturbed by the retrieval equipment. This test plan describes ongoing efforts to test the dig-face characterization concept at the INEL's cold test pit using a simplified prototype deployment apparatus and off-the-shelf sensors. FY-94 field experiments will explore problems in object detection and classification. Detection and classification of objects are fundamental to three of the four primary functions of dig-face characterization during overburden removal. This test plan establishes procedures for collecting and validating the dig face characterization data sets. Analysis of these data will focus on testing and further developing analysis methods for object detection and classification during overburden removal.

INEL-94-0210 Large-Scale Demonstration Test Plan for Dig-Face Data Acquisition System. The dig-face characterization system at the INEL was initially demonstrated in FY-93 at the cold test pit. In FY-94, work began in support of a large-scale demonstration coordinating the various facets of a prototype dig-face remediation operation including characterization, contaminant suppression, and cold waste retrieval. This test plan describes the activities that will be performed during the winter of FY-95 that are necessary to assess the performance of the data acquisition and display system in its initial integration with hardware developed in the Cooperative Telerobotic Retrieval program. The six specific objectives of the test are determining system electrical noise, establishing a dynamic background signature of the gantry crane and associated equipment, determining the resolution of the overall system by scanning over known objects, reporting the general functionality of the overall data acquisition system, evaluating the laser topographic functionality, and monitoring the temperature control features of the electronic package.

EGG-WTD-11062 Dig-Face Characterization Development Plan. February 1994. This plan documents recommendations for developing a characterization system to be used at the dig face during the retrieval of buried waste. These recommendations can be used to guide system development and maximize the benefit and applicability of a characterization system to DOE and non-DOE buried waste remediation efforts.

Draft Final Report. A dig-face characterization system incorporates three technologies: a sensor subsystem, a deployment subsystem, and a data-handling subsystem. In all cases, these subsystems supply the basic capability to (a) collet characterization data at the waste excavation dig face, (b) analyze the data in near real time, and (c) provide information 
feedback to manage the ongoing waste retrieval effort. A prototype system incorporating basic forms of each technology element was assembled in FY-93 to begin evaluating the dig-face characterization concept. The sensor suite used during the course of the experimental work included three types of metal detectors, a simple volatile gas sensor and a ground radar system. A comprehensive radiation sensor group and a volatile gas sensor are currently being assembled for deployment in FY-95. Deployment for the prototype system was accomplished with a manually operated fiberglass trolley. The trolley was designed for horizontal excavation and is not easily adaptable for working on vertical excavations.

Results from a set of controlled dig-face characterization experiments using a prototype system were assembled and used to collect multisensory data during excavation of a series of pits containing simulated waste materials. The data revealed progressively finer details of subsurface materials as excavation advanced, confirming the fundamental technical benefit of the dig-face characterization approach. The experimental data also created an experience base from which to begin developing methods for classifying and ultimately identifying specific subsurface conditions.

Results of Performance Tests on Chemical and Radiation Measurement Systems for Use at a Dig Face. Chemical and radiation measurement systems are being developed for use at a dig face to provide sensing capability during excavation of previously buried waste. It is believed that online dig-face characterization will reduce environmental, health, and safety risks during cleanup of buried waste sites, as well as improve the efficiency of cleanup processes. This report describes progress in developing three measurement systems: (a) a gamma/neutron monitor that scans the dig face for high levels of radiation prior to excavation, (b) a Ge spectrometer that identifies specific radionuclides located with the gamma/neutron monitor, and (c) a prompt gamma neutron activation analysis (PGNAA) system that measures the presence of chlorine and chlorinated compounds often associated with hazardous waste. The Ge spectrometer and PGNAA system also will provide offline but onsite capability of radionuclides and elemental identification of excavated waste prior to handling, treatment, and transportation or disposal.

\section{TTP ID142004: Very Early Time Electromagnetics (VETEM)}

EGG-WTD-11354 Test Plan for Data Acquisition and the INEL Cold Test Pit. The Buried Waste Integrated Demonstration Very Early Time Electromagnetic System is a high-frequency early time electromagnetic method for detailed mapping of the electrical conductivity and relative dielectric properties of the shallow subsurface. The field work described in the plan is designed to obtain a high-density 3D dataset with the high-frequency sounder over the characterization cell of the cold test pit. The dataset will be used in systems analysis and in developing interpretational schemes.

USGS. First Quarterly Report for the VETEM Project. This report details work accomplished during the first quarter of 1994.

USGS. Second Quarterly Report for the VETEM Project. This report details work accomplished during the second quarter of 1994. 
USGS. Third Quarter Report for the VETEM Project. The 3rd Quarterly Report consists solely of the report of the 2nd VETEM meeting held July 11, 1994, in Golden, Colorado.

A discussion of 3D EM modeling for very early time sounding of shallow targets using integral equations followed with a discussion of problems with forward modeling of a layered earth and with 3D modeling using staggered grids were given. Practical application of the 3D formulation on massively parallel computers was presented. There is good progress in the development of this 3D high-frequency forward and inverse modeling using the finite element method. Frequency domain-time domain formulation for general dispersive media was presented.

Three papers were presented relating to interpretation of results of TDEM surveys at the cold test pit. A systematic analysis of the problems to be anticipated when applying VETEM over a $1 \mathrm{D}$ earth and a status report on developing a 2-1/2 D frequency domain algorithm for computing the transient response when displacement currents are included were presented.

A preliminary analysis of the superposition of lateral waves versus diffusion effects from a vertical magnetic dipole over a layered half-space was presented followed by an illustration of high-frequency sounder (HFS) results over five test sites including the cold test pit. Problems with the HFS were illustrated, but not all the problems can be readily explained at the present time. Experimentation with the HFS to test for repeatability and precision was conducted. Factors entering into VETEM hardware performance analysis were explored, and a status report on the design of VETEM was given.

USGS Annual Progress Report. One-dimensional (1D) modeling algorithms were developed, tested, and are being used in physical analysis of the buried waste problem, interpretation of field data, and in the systems analysis devoted to instrument design. The code, with a friendly graphical user interface, will be transferred to industry in FY-95. Development of multidimensional modeling algorithms, essential for interpreting 3D targets, is under way and the complimentary algorithms will be used in numerical experiments and systems analysis in FY-95. Soil samples in the vicinity of the cold test pit are collected and analyzed so that accurate modeling of both the host soil and the targets with the calibration cell can be completed.

The prototype time-domain instrument is near completion, and both it and the second generation HFS will begin field testing in October 1994. System analysis is ongoing to ensure that the instruments do not contain unique system responses that can severely limit interpretation or that they are not optimized for the buried waste problem.

A $1 D$ interpretation of HFS data acquired at the cold test pit gave very realistic estimates for the thickness, dielectric permittivity and electrical conductivity properties of the cap covering the waste. The 3D inversion of data transformed from the time to the frequency domain, and electromagnetic migration of time-domain data with a host estimated taken for the HFS $1 D$ interpretation gave reasonable estimates of the depth to basalt, volume of waste and location lateral boundaries. 
The development of an aggressive technology transfer plan has been accomplished and a working relationship with the Buried Waste Integration Development technology transfer office.

\section{TTP ID142005: Virtual Environment Generation of Buried Waste}

Draft Technology Evaluation Report. This report will be finalized in FY-95 (INEL-94-0080). A project entitled Virtual Environment Applications for Buried Waste Characterization was initiated within the Buried Waste Integrated Demonstration Program in FY-94. This project is a research and development effort to identify and examine issues, needs, and the feasibility of generating virtual environments that, through utilization of available characterization and other data, might assist in remediation of buried waste. This document describes the progress and results from this project during the past year.

Draft Functional Requirements and Direction Document. Virtual Environment Generation of Buried Waste is a new effort to investigate the issues, requirements, and feasibility of developing a virtual environment to assist in characterizing and remediating buried waste. Initial work involved generating rapid prototype environments, using the characterization cell, an engineered waste pit containing buried objects, in the cold test pit at the INEL as a basis.

Efforts include developing sensors and deployment techniques for use in conducting buried waste pit surveys, survey data analysis and interpretation, data fusion efforts, characterization and retrieval methodologies, etc. Engineering information provides data for all objects in the complex, including buried waste container size, construction, content, location, and weight. Magnetometer measurements show that while anomalies in the magnetic field can basically be correlated to locations containing waste objects of ferrous material content, underlying structure has a confounding influence on the magnetic field and interpretation thereof.

Three different classes of virtual environments for the characterization cell were constructed during the rapid prototype stage, (a) three-dimensional walkthrough models of the characterization cell and of the entire cold test pit were constructed using a commercial software package for modeling and rendering environment, (b) visual data base model that is a three-dimensional modeling/editing environment and a separate runtime interactive environment, (c) a volume data set consisting of information from the four parallel planes was constructed by concatenating the individual data sets that allow the user to rotate and translate the data set, thus allowing examination from arbitrary points.

\section{TTP ID142011: Gravity Field Measurements}

Draft Test Plan. Gravity Field Measurements. The objectives of this microgravity survey are to evaluate the gravity field in the vertical direction only. The gravity meter will be brought to the cold test pit by a subcontractor and used to make measurements at predefined points over the cold test pit. These data will be collected in their uncorrected form, and adjustments will be determined for free air correction, instrument drift (including level drift), instrument tares, tide, elevation, etc., to provide a local observed gravity at each points. 
Gravity Field Measurements Capability Report. This paper compiles some recent work in the field of making microgravity measurements to aid in the characterization of buried waste pits. It looks at the possible technical advantages and disadvantages of the use of a gravity gradiometer system in furthering this work. It describes some of the existing and proposed instruments for measuring gravity and gravity gradients and gives a brief status of those pieces of hardware.

\section{TTP RL342002: High-Resolution Imaging of Buried Waste Using Radar Array}

PNL Report. Draft Test Plan for PNL Demonstration. This technology test plan defines the equipment, test site, and test process necessary to demonstrate the capabilities of the Ground-Penetrating Holographic (GPH) Impulse Radar Array system to characterize simulated buried waste in the laboratory. The test bed will be a frame containing INEL and Hanford soil located in the Engineering Development Laboratory (EDL) at Richland, Washington. Targets simulated waste containers will be buried at known locations and depths under the soil. The $5 \mathrm{GHz}$ antenna array and computer system will be mounted to the transport trailer configured as a field deployable GPH imaging system. The GPH system will be scanned over the test bed soil and real-time images of the targets will be generated. The images will be analyzed to determine the operational capability of the GPH system. 


\section{WASTE CHARACTERIZATION}

TTP ID121212: Radiological and Hazardous Materials Measurement System

EGG-WTD-10359, Slow Neutron Interrogation Facility, February 1994. This report discusses the design and testing of the Slow Neutron Interrogation Facility for the detection of transuranics in nuclear waste.

Test Plan for RHMMS. This test plan describes prompt gamma neutron activation analysis (PGNAA) measurements to be conducted to assess the potential usefulness of nonintrusive, nondestructive elemental assay for the safe excavation, radiomonitoring, handling, sorting, transportation, treatment, and disposal of TRU, LLW, mixed, and hazardous waste. The objectives of the experiments described in this test plan are to develop methods for qualitative and quantitative characterization of elemental constituents in containerized waste. The objective of this year's PGNAA task is to develop a counting and analysis protocol for quantifying the amounts of chlorine of boron present in waste drums to be assayed for fissile materials. Since the methods to be used are not fully developed, this test plan provides a mechanism by which the principal investigators have thought through the objective of these tests and the steps involved to accomplish them in a safe and high-quality manner.

White Paper for Photon Analysis Spectrometer System (PASS). Photon Analysis Spectrometer System (PASS) was developed to provide sensitive measurement of the plutonium in soil and other samples. PASS is capable of automatically measuring radionuclide activity concentrations in up to 100 samples per day at remediation sites.

\section{TTP ID142015: Excavated Waste Assay (EWA)}

Draft Systems Requirements Report was delayed and will be completed in FY-95 (INEL-94-0141).

INEL-94-0105 Plan for the Testing of Radiation Measurement Instrumentation Intended for Use at an Excavated Site, November 1994. This plan describes performance tests to be made with ionizing radiation measurement instrumentation designed and built for in-field assay at an excavation site. One instrument measures gross gamma-ray and neutron fields and the other identifies gamma-ray emitting radionuclides and also is capable of assaying for selected hazardous materials. These instruments will be operationally tested to verify that original specifications have been met and performance tested to establish and verify that they have the potential to function as intended at an excavation site.

INEL-94-0141 Draft FY-94 Excavated Waste Assay Evaluation Report. This report describes the present state of the Excavated Waste Assay (EWA) system, present and projected capabilities, and FY-95 plans. EWA is being developed to provide characterization capabilities in situations where knowledge of the transuranic content of retrieved buried waste and treated wastes is required. The objective of EWA is to enable segregation of waste at the $10 \mathrm{nCi} / \mathrm{g}$ level at throughput rates acceptable to retrieve and treat processes. 
TTP ID142016: High-Speed Digital Radiography \& Computed Tomography of Waste Drums

Draft Test Plan. Test Plan for Digital Radiography and Computed Tomography (DRCT) of Containerized Waste. This draft test plan describes the initial set of experiments to be performed on calibration waste drums and phantoms using the present linear detector array and an area detector under development. These tests are designed to demonstrate that digital radiographic and tomographic information, useful to the characterization of a waste package, can be provided in nearly the same timeframe as current, nonquantitative Real-Time Radiography (RTR) systems. As the logistics expand to include real waste drums and other waste package forms, this test plan will be updated as needed to fulfill BWID requirements.

Status report on the Digital Radiography and Computed Tomography (DRCT) scanner. The Digital Radiography and Computed Tomography (DRCT) scanner, under refurbishment and upgrade as part of the DRCT of Waste Containers (ID142016) project, was tested for operability and performance specifications. The scanner was shown to function as specified, with the exception of some software operation problems that have since been corrected. In addition, calibration drums from the INEL were scanned as part of the acceptance testing. This report summarizes the results of the acceptance tests of the DRCT scanner and calibration drum measurements.

\section{TTP SF221209: Nondestructive Assay/Nondestructive Examination of Low-Level Waste Drums}

Lawrence Livermore National Laboratory Report on University/Industry Participation. This report documents the findings and results of scanning a characterized mock-waste (standard) drum containing representative low-level waste and transuranic waste items using active and passive computed tomography (A\&P CT). 


\section{RETRIEVAL}

\section{TTP ID121210: Mobile Transuranic Monitoring Laboratory}

EGG-WTD-11208 Test Plan for Preparing the Rapid Transuranic Monitoring Laboratory

Field Deployment. This test plan describes experimental work that will be performed during FY-94 to prepare the Rapid Transuranic Monitoring Laboratory (RTML) for routine field use by DOE Environmental Restoration and Waste Management programs. The RTML is a mobile, field-deployable laboratory developed at the INEL that provides a rapid, cost-effective means of characterizing and monitoring radioactive waste remediation sites for low-level radioactive contaminants. Analytical instruments currently installed in the RTML include an extended-range, germanium photon analysis spectrometer with an automatic sample changer; two, large-area, ionization chamber alpha spectrometers; and four alpha continuous air monitors. The RTML was field tested at the INEL during June 1993 in conjunction with the Buried Waste Integrated Demonstration's remote retrieval demonstration. The major tasks described in this test plan are to (a) evaluate the beta detectors for use in screening soil samples for ${ }^{90} \mathrm{Sr}$, (b) upgrade the alpha spectral analysis software programs, and (c) upgrade the photon spectral analysis software programs.

INEL-94-0246 3-Volume Report, Volume 1 - Progress Report on ${ }^{90} \mathrm{Sr} /{ }^{238} U$ Analyzer and Alpha Continuous Air Monitor, Volume 2 - Rapid Monitoring of Soil, Water, and Air Dusts by Direct Large-Area Alpha Spectrometry, and Volume 3 - Photon Analysis Spectrometer System.

Volume 1 - The laboratory was designed to measure low-level concentrations of transuranic and fission product contaminants in samples of soil, settled dust, and air collected at buried radioactive waste remediation sites. This report describes the ${ }^{90} \mathrm{Sr}$ detector and the new generation alpha continuous air monitor and the existing analysis capabilities of the RTML.

Volume 2 - During retrieval and disposition of wastes containing transuranic (TRU) elements, continuous monitoring of the air, water, and soil for alpha emitters is required to ensure that safety limits are not exceeded and that the waste itself is not disturbed unknowingly. This report describes the direct measurements by alpha spectrometry and their ability to identify TRU radionuclides under field conditions.

Volume 3 - This report describes the Photon Analysis Spectrometer System, which measures the activity concentrations of transuranic and activation and fission product contamination in soil, smear, and air filter samples, to provide more accurate results and more realistic uncertainties.

EGG-WTD-10935, Field Test of Rapid TRU Monitoring Laboratory. A field test of the Rapid Transuranic Monitoring Laboratory (RTML) developed at the INEL was conducted as part of a demonstration sponsored by the Buried Waste Integrated Demonstration (BWID). The RTML is a mobile, field-deployable laboratory developed for use at buried radioactive waste remediation sites to allow onsite preparation and analysis of soil, smear, and air filter samples for alpha and gamma-emitting contaminants. Analytical instruments installed in the RTML include an extended range, germanium photon analysis spectrometer 
with an automatic sample changer, two large-area ionization chamber alpha spectrometers, and four alpha continuous air monitors. The performance of the RTML was tested at the Test Reactor Area and cold test pit near the RWMC at the INEL. Objectives, experimental procedures, and an evaluation of the performance of the RTML are presented.

\section{TTP ID142002: Real-Time Monitoring of Transuranic-Contaminated Dust}

INEL-94-0003 Test Plan for Glove-Box Testing with the Real-Time TRU Dust Monitor. This test plan describes the experimental details for the bench-scale testing of the real-time transuranic dust monitor (RTDM) to be performed at the INEL. The purpose of these experiments is to establish the feasibility of the RTDM as a stand-alone monitoring device for airborne transuranics and to investigate the optimal performance parameters and operational limits of the prototype. Test objectives, experimental procedures, and data quality objectives are included in the plan.

\section{TTP ID142006/TTP ID142007: Waste Conveyance/Technology End Effector}

Project Management Plan for Waste Conveyance/Innovative End Effector. The Project Management Plan as prepared for the Buried Waste Integrated Demonstration (BWID) Waste Conveyance for Buried Waste Retrieval (TTP ID142006) and the Innovative End Effector for Dust-Free Dumping (TTP ID14207). This plan was prepared in accordance with company procedures and the BWID program directives. This plan serves as the Task Baseline Agreement (TBA) between the performers and the performers' organization, and the BWID program manager.

EGG-WTD-11185 Draft Test Plan for Remove Conveyance/Innovative End Effector. Dumping dry soil into a funnel/dumpster arrangement has been found to be the primary mechanism for dust generation during the retrieval of buried transuranic (TRU) waste. The primary goal of the innovative end effector is to reduce dust generation and the potential spread of airborne contaminants during dumping. The remote conveyance system is aimed at developing a remotely controlled vehicle to convey retrieved waste that will operate on variable terrain and remove workers form the hazardous zone. This test plan will describe demonstration objectives, data quality objectives, equipment operation, and methods for collecting data during the demonstration.

INEL-94-10173 Final Technology Evaluation Report. This document will include findings of the demonstration to be performed. The report is formatted so it can easily be interpreted and used as the basis for follow-on design work.

Video Production. Videos documenting the test for data purposes were prepared. In addition, other videos will be produced from the raw footage. The videos are professionally produced, with narration and captions included. 
TTP ID142008: Remote Retrieval Demonstration

EGG-WTD-11446 Buried Waste Integrated Demonstration Human Engineered Control Station Final Report. This document describes the Human Engineered Control Station (HECS) project activities including the conceptual designs. The purpose of the HECS is to enhance the effectiveness and efficiency of remote retrieval by providing an integrated remote control station. The HECS integrates human capabilities, limitations, and expectations into the design to reduce the potential for human error, provides an easy system to learn and operate, provides an increased productivity, and reduces the ultimate investment in training. The overall HECS consists of the technology interface stations, supporting engineering aids, platform (trailer), communications network (broadband system), and collision avoidance system.

\section{TTP ID142009: Cooperative Telerobotic Retrieval}

INEL-94-0210 Large-Scale Demonstration Test Plan for Dig-face Data Acquisition System. The dig-face characterization system at the INEL was initially demonstrated in FY-93 at the cold waste pit. In FY-94, work began in support of a large-scale demonstration coordinating the various facets of a prototype dig-face remediation operation, including characterization, contamination suppression, and cold waste retrieval. This test plan describes the activities that will be performed during the winter of FY-95 that are necessary to assess the performance of the data acquisition and display system in its initial integration with the hardware developed in the Cooperative Telerobotic Retrieval program. The six specific objectives of the test are determining system electrical noise, establishing a dynamic background signature of the gantry crane and associated equipment, determining the resolution of the overall system by scanning over known objectives, reporting the general functionality of the overall data acquisition system, evaluating the laser topographic sensor's functionality, and monitoring the temperature control features of the electronic package.

\section{INEL-94-0035 Cooperative Telerobotic Retrieval System Test Plan for FY-94. A} comprehensive system for effective remediation of buried waste involves equipment that can perform remote operations at a buried waste site. The Cooperative Telerobotic Retrieval system was funded by the BWID program that evaluates, validates, and demonstrates technologies that encompass the entire remediation process from characterization to postmonitoring. The FY-94 effort included the development, testing, and evaluation of a Cooperative Telerobotic Retrieval system that can perform remote selective retrieval of buried waste. This system includes two robotic manipulators installed on a delivery system and used in tandem activities to perform a variety of tasks. The system can selectively remove debris from around the article of interest, retrieve that article, deploy tools such as dig-face characterization and a vacuum, and lend other support for retrieval activities. These efforts are being performed in preparation for the FY-95 BWID integrated demonstration at the INEL. This test plan identifies key objectives and how these objectives will be quantified, testing operations, test sequencing, operational issues, and contingency.

BWID Evaluation Report. In an attempt to save costs, requested that this a formal evaluation report not be generated. A letter report was deemed satisfactory for accomplishing the milestone. Multiaxis Crane Letter Report - The crane system described in 
this document offers capability of remotely performing a variety of tasks as well as considerable amounts of work. This project involved the integration of an electronic control system with a multiaxis crane (MAC) system. The crane is constructed in accordance with standard industry crane design and fabrication practices and consists of three bridges, three trolleys, three chain hoists, and a two-level supporting structure. The MAC system upgrade was performed to satisfy several objectives. The primary objectives was to show the feasibility of remotely controlling the system. This involved operations implementing both teleoperation and/or robotics operations of the equipment. A goal of the project was to show the ease of integrating a sophisticated supervisory control system with commercially available and already fielded hardware.

\section{TTP ID142019: Cryogenic Cutting System Demonstration}

Test Plan for Cryogenic Cutting. The Cryogenic Jetting System (CJS) was developed for the purpose of cutting or abrading various materials without the addition of a secondary waste stream. This document describes the test plan for the CJS demonstration and testing for the Buried Waste Integrated Demonstration. The purposes of the test plan are to establish test parameters so that the demonstration results are deemed useful and usable, and that the demonstration is performed in a safe manner within all regulatory requirements.

Cryogenic Bin and Box Opening System Demonstration-Final Report. The objective of the Cryogenic Bin and Box Opening System Demonstration was to remotely deploy a cutting jet composed of liquid nitrogen for the purpose of opening a steel waste bin and plywood waste box. This process produces no secondary waste, makes a very small cut that minimizes chips, does not generate heat that is a concern with plasma arc cutting, and is not affected by materials below wood surfaces, which is a concern for saw cutting. The existing Cryogenic Cutting System underwent extensive upgrades to improve cutting effectiveness, and a new system was designed to attach to a gantry crane located at the North Boulevard Robotics Center.

\section{TTP ID142020: Machine Health Monitoring}

Test Plan. System Health Monitoring and Prediction Program Test Plan (DRAFT) Technology Test. The System Health Monitoring and Prediction (SHM\&P) Program is a system intended to ensure that remote equipment can be analyzed and problems solved before failure of remotely operated equipment housed in hazardous environments. The system is being developed specifically for monitoring equipment used for remediation of hazardous waste sites at the INEL's Radioactive Waste Management Complex (RWMC). The Buried Waste Integrated Demonstration (BWID) is funding the demonstration, testing, and evaluation of the SHM\&P Program covered in this test plan. This document covers testing at the INEL, as funded by BWID.

EGG-WTD-11492 System Health Monitoring and Prediction Technology Evaluation Report. This report represents a "white paper" discussion of the status of the System Health Monitoring and Prediction (SHM\&P) project. Because the project is not scheduled for final demonstration until FY-95, this report is not the official Technology Evaluation Report submitted upon completion of a demonstration. Rather, the intent is to convey the progress 
of the INEL's SHM\&P technology. The objectives of SHM\&P are to develop a monitoring and diagnostic system for remotely operated, hydraulic equipment that predicts impending system failures, and improves cleanup operations by minimizing downtime and human exposure to hazardous environments. The technical aspects of the project include the integration of existing sensor technology, development of online monitoring systems, development of hydraulic failure algorithms, and the design of an expert system-based diagnostic system that predicts hydraulic system failures.

\section{TTP OR142003: Remote Excavation System}

Oak Ridge Document. Draft Test Plan-Remote Excavation Demonstration at Oak Ridge. The Remote Excavation Demonstration at the Oak Ridge Hill Cut Test Facility will test and demonstrate the use of remotely operated excavation technology for a specific class of buried waste remediation. The primary demonstration objectives are to demonstrate Remote Excavation System (RES) applicability for retrieval of concrete waste containment casks and to quantify reduction in operator radiation exposure risks.

ORNL-TM-12770 Oak Ridge. Explosive Ordnance Disposal Technology Demonstration Using the TeleRobotic Small Emplacement Excavator. The small emplacement excavator (SEE) is a rugged military vehicle with backhoe and front loader used by the U.S. Army for explosive ordnance disposal (EOD), combat engineer, and general utility excavation activities. In order to evaluate the feasibility of removing personnel from the vehicle during high-risk EOD excavation tasks, a development and demonstration project was initiated to evaluate performance capabilities of the SEE under telerobotic control. This feasibility study was performed at the Redstone Arsenal to help define requirements for further joint service development activities. Development of a telerobotic SEE (TSEE) was performed by Oak Ridge. A technology demonstration of the TSEE was conducted at McKinley Range, Redstone Arsenal, Huntsville, Alabama. The primary objective of the demonstration was to evaluate and demonstrate the feasibility of remote EOD.

\section{TTP RL342001: Contaminated Material, Excavation, Handling, and Retrieval System}

Pacific Northwest Laboratory (PNL) Report. Draft Functional Design Criteria for a Mobile Solid Waste Retrieval System. The functional design criteria and preliminary equipment specifications for a transportable solid waste retrieval system are contained in this report. The purpose of the facility is to retrieve and package contaminated solid waste, solids, transuranic (TRU) waste, and low-level mixed waste for above-ground storage before processing into a more stable form. The system offers a sealed environment, shielded personnel working zones to reduce the exposure levels as low as reasonably achievable (ALARA), and air ergonomic work environment to increase worker efficiency and reduce the level of staff required to conduct operations. 


\section{CONTAINMENT/STABILIZATION}

\section{TTP ID111202: In Situ Vitrification}

ASTM Report on Graphite Venting on ISV The Effect of Graphite Venting on ISV Processing of Low-Permeability Soils. In situ vitrification (ISV) is a promising technology for remediating buried waste and contaminated soil sites. Concerns exist, however, that low soil permeabilities may limit vapor transport away from the advancing ISV melt front, causing a melt expulsion that breaches ISV containment. A potential solution may be the use of a graphite rod placed vertically through the area being processed that acts as a "preferred pathway" in venting generated vapors through the ISV melt. To evaluate this engineering solution, two ISV lab tests were conducted at the INEL using a low-permeability clay material. One of the tests used the graphite rod concept, while the other did not. Test results found that the graphite rod is effective in preventing the buildup of pressures beneath the ISV melt. The graphite rod may also limit the amount of entrained particulate released to the off-gas system during ISV processing.

ASTM Report on Lab Test Results Vapor Trans Lab-Scale Tests on ISV Vapor Transport Phenomena. In situ vitrification (ISV) is a promising technology for remediating buried waste sites and contaminated soil sites. However, concerns exist that low soil permeabilities may limit vapor transport away from the advancing melt front and cause a melt expulsion that breaches ISV containment. As a result, two ISV lab tests were conducted at the INEL using INEL soil (permeability: $10^{-6} \mathrm{~cm} / \mathrm{s}$ ) and a low-permeability $\left(10^{-10} \mathrm{~cm} / \mathrm{s}\right)$ clay material. The clay test also had a ceramic tube inserted vertically through the center of the area being melted to provide one-dimensional data on vapor transport. Results confirm that low soil permeabilities can limit vapor transport away from the advancing ISV melt front. In addition, peak pressures inside the ceramic tube were significantly greater than those outside the tube, indicating the importance of horizontal vapor transport around the advancing ISV melt front.

\section{TTP ID142012: In Situ Encapsulation}

EGG-WTD-11410 In Situ Encapsulation Bench-Scale Demonstration Test Plan. This test plan describes the test objectives and procedures for the laboratory-scale demonstration of in situ waste encapsulation of buried waste using a synthetic analog of natural cement.

In Situ Encapsulation of Bench-Scale Demonstration Final Report. This report describes the test objectives, procedures, and results of the laboratory-scale tests of in situ waste encapsulation of buried waste using a synthetic analog of natural cement.

\section{TTP ID142014: Innovative Grout Demonstration}

EGG-WTD-11350 Innovative Grouping/Retrieval Demonstration Test Plan. This test plan describes procedures for the Innovative Grout/Retrieval Demonstration. The plan includes pit construction, jet grouping, expansion grout fracturing, retrieval techniques and air, hydrological and long-term monitoring. 
INEL-94-0001 Final Report for Innovative Grout/Retrieval Demonstration. This report presents the results of an evaluation of an innovative retrieval technique for buried transuranic waste. The technique involves first grouting the buried soil waste matrix with a jet-grouting procedure, applying an expansive demolition grout to the matrix, and retrieving the debris. The grouted matrix provides an agglomeration of fine soil particles and contaminants that results in an inherent contamination control during the otherwise dusty retrieval process. Contained in this report are details on all phases of the proof-of-concept demonstration including the pit construction, jet grouting activities, application of the demolition grout, and the actual retrieval of the grouted pit. A quantitative evaluation of aerosolized soils and rare earth tracer spread is given for all phases of the demonstration, and these results are compared to a baseline retrieval activity using conventional retrieval means.

\section{TTP RL421212: Monolithic Confinement}

Westinghouse Hanford Document. Monolithic Confinement of Radioactive Waste Test Plan. This task will demonstrate in situ treatment of fractured rock and geologic media at an uncontaminated site and will be evaluated to determine the applicability of treatment of radioactive and hazardous materials underlying the Radioactive Waste Management Complex. Testing of equipment, materials, and methodologies will be conducted at a Bureau of Land Management test site, an INEL site, the Hanford Site, and Brookhaven National Laboratory.

Westinghouse Hanford Document. Draft FY-94 Technology Report. Monolithic confinement was successfully tested by the INEL and Westinghouse Hanford Company at a test area near the INEL for the Buried Waste Integrated Demonstration (BWID), Office of Technology Development (OTD). Monolithic confinement is a method to create a barrier to water movement in fractured rock underlying buried waste by cementing the cracks of the rock under ground. The process also immobilizes contaminants in the waste or underlying rock.

The technology provides a positive barrier to further migration of buried waste contaminants particularly to underlying aquifers without digging up the waste or disturbing the site. Forming a subsurface barrier is a cost-effective way to eliminate the further migration of contaminants that might be present within underlying basalt. This technique is useful on any buried waste site where contaminant spread is a problem and water penetration through the waste needs to be reduced. 


\section{TREATMENT}

\section{TTP AL142002: Treatment of BWID Off-Gas Using Nonthermal Plasma}

Los Alamos National Laboratory Document Test Plan for Secondary Treatment of BWID Off-Gas Using Nonthermal Plasma. This project addresses Ex Situ Treatment/Secondary Treatment Technologies of the BWID Program. Recent analyses conducted to address the waste treatment needs of the INEL BWID revealed that there is a need for technologies that can handle off-gas from high-temperature thermal primary treatment units. Test plans and field demonstration units will be tailored for specific waste streams. We will evaluate nonthermal plasma (NTP) equipment as a secondary off-gas treatment stage for the BWID primary-stage thermal arc-melter. This evaluation will focus on removing hazardous organics, $\mathrm{SOx} / \mathrm{NOx}$, and high-vapor pressure metals (HVPMs) in off-gas.

\section{TTP ID121211: Ice Electrodes}

EGG-WTD-11128 Design and Construction of an Ice Electrode Bench-Scale System. A continuous-flow, bench-scale system has been designed and fabricated to use an ice electrode for the continuous removal of metals from solution. The system uses a rotating drum covered with a platinum-coated niobium screen as the anode. Ice is coated on the stainless steel cathode where metals are plated. Scrappers are provided for removing the plated metals from the ice surface, directing the metals into the center of the drum where they are collected. The system is controlled with an ElectroSynthesis Electrochemical Model 7630 DC Power Supply/Controller, with cooling to the system provided by a $12,000-\mathrm{Btu}$ chiller.

TTP ID132006: BWID Waste Form Integration and Limits

Report - Waste Stream Properties of Vitrified Rocky Flats TRUW with Different Waste Loadings. Leach rates, phase structures, and mechanical properties of simulated Rocky Flats Plant first- and second-stage sludge vitrified in an arc melter are described as a function of waste to soil fraction and method of devitrification to produce the glass-ceramic waste form. Volatile, hazardous, and transuranic (TRU) surrogate metals were added to assess dissolution effects. Zirconia and titania were also added to confirm their ability as transuranic-surrogate getters.

\section{TTP ID132010: BWID Thermal Kinetics}

EGG-WTD-10918 Modeling ISV Power Control \& Lab Test Simulations Using FIDAP and $V U L C A N$. Numerical studies of heat transport and melting in soil are presented in this report. The commercial finite element code FIDAP is used to model a 2-D In Situ Vitrification (ISV) system. Included in the model is the calculation of the electric field and heat transport. A proportional-integral-derivative controller is implemented in a FIDAP user subroutine to control the ISV electrode boundary condition that controls the electrical power to follow a specified power curve. Also included in this report is the heat transport analysis of an ISV lab test conducted at the INEL. The VULCAN computer code is used to model this 3-D experiment. VULCAN predictions for melt growth, melt depth, and width 
are slightly smaller than the experiment, while the energy and power control are the same as the experiment.

WTD-94-057 Small-Scale ISV Phenomenological Porous Media Experiments. In support of the INEL ISV program to provide validation data for the TOUGH code, a series of experiments have been performed in which a cylindrical volume of water-saturated porous media was heated from the center using a submerged cartridge heater. Visual observations of steam production were obtained using a laser light sheet to illuminate the region above the upper surface of the porous media. Temperatures and pressures throughout the porous media were continuously monitored using a computerized data acquisition system. An initial constant heat flux test demonstrated that centering of the glass beads could occur in the vicinity of the heater, forming an effective nonporous barrier that prevented further transport of liquid or vapor to or from the heater surface and thermally insulated the heater surface. Maximum heater temperatures were limited in subsequent tests through the use of a temperature controller. Outward movement of the liquid/vapor interface was slow, typically requiring more than 10 hours to move only 1 in. radially outward. Higher set-point temperatures resulted in more rapid movement of the interface. Capillary effects caused the pressures within the system to drop when the water level was below the porous media surface. The magnitude of the pressure drop is related to the characteristic inter-particle spacing and is largest for small particles. After the initial capillary-induced pressure drop, the gauge pressures eventually return to zero as the porous media dry out.

EGG-WTD-10942 Off-Gassing Induced Tracer Release from Molten Basalt Pools. Two in situ vitrification (ISV) field tests were conducted at the INEL during the summer of 1990 to assess ISV suitability for long-term stabilization of buried waste that contains transuranic and other radionuclide contaminants. The ISV process uses electrical resistance heating to melt buried waste and soil in place, which upon cool down and resolidification fixes the waste into a vitrified (glass-like) form. The analysis presented in this report indicates that dissolution of tracer oxides into basaltic melts can be expected with subsequent tracer molecular or microparticle carry-off by escaping gas bubbles, which is similar to adsorptive bubble separation and ion flotation processes employed in the chemical industry to separate dilute heavy species from liquids under gas-sparing conditions. Gaseous bubble escape from the melt surface and associated aerosolization is believed to be responsible for small quantities of tracer ejection from the melt surface to the cover hood and off-gas collection system. Methods of controlling off-gassing during ISV would be expected to improve the overall retention of such heavy oxide contaminants during melting/vitrification of buried waste.

\section{TTP ID132011: BWID Arc-Melter Vitrification}

INEL-94-0004 Test Plan for BWID Phase 2 Electric Arc Melter Vitrification Tests. This test plan describes the Buried Waste Integrated Demonstration (BWID), Phase 2, electric arc melter, waste treatment evaluation tests to be performed at the U.S. Bureau of Mines (USBM) Albany Research Center. The BWID Arc Melter Vitrification Project is being conducted to evaluate and demonstrate existing industrial arc melter technology for thermally treating mixed transuranic-contaminated wastes and soils. Phase 1 baseline tests, performed during fiscal year 1993 at the USBM, were conducted on waste feeds representing incinerated buried mixed wastes and soils. In Phase 2 , surrogate feeds will be 
processed that represent actual as-retrieved buried wastes from the INEL's Subsurface Disposal Area at the Radioactive Waste Management Complex.

EGG-WTD-11138 Arc Melter Demonstration Baseline Test Results. This report documents the results of an initial series of pilot-scale electric arc melter baseline tests conducted on five mixtures of surrogate buried mixed wastes and soil that simulate those at the INEL. The results show the feasibility of using existing industrial arc melter technology for treating "previously incinerated" buried mixed wastes and soils on a production basis. Extensive additional design, testing, and evaluation are required to optimize the arc furnace system and improve operations. Modifications such as an enhanced feed system, overall system containment, and remote tapping operation will enable application of the existing technology represented by the USBM system for radioactive waste treatment.

EGG-WTD-10981 Baseline Test for Arc Melter Vitrification of INEL Buried Waste, Vol I and II. This report presents field results and raw data from the Buried Waste Integrated Demonstration (BWID) Arc Melter Vitrification Project Phase 1 baseline test series conducted by the INEL in cooperation with the USBM. The baseline test series was conducted using the electric arc melter facility at the USBM Albany Research Center in Albany, Oregon.

\section{TTP ID142010: Modeling of Thermal Plasma Arc Technology}

Mid-Year Progress Report for Modeling of Plasma Arc Technology. A general, reliable, and accurate computer model of the plasma arc - Joule Heating Waste Treatment process is under development by modifying existing codes. The value of this computer model will be to (1) aid in understanding the plasma arc - Joule Heating Process as applied to buried waste or exhumed buried waste (2) help design melter geometry and electrode configuration, (3) calculate process capability of vitrifying waste (i.e., tons/hour), (4) develop efficient plasma and melter operating conditions to optimize the process and/or reduce safety hazards, (5) calculate chemical reactions during vitrification of waste to track chemical composition of off-gas products, and composition of final vitrified waste form, and (6) help compare the designs of different plasma-arc facilities.

\section{TTP RL332016: Graphite DC Arc Plasma Furnace}

PNL Report. Diagnostics Development for the Mark II Arc Furnace Progress Report. A "national Laboratory-University-Industry" collaboration has been established between PNL, Massachusetts Institute of Technology (MIT), and the small businesses Electro-Pyrolysis, Inc. (EPI) and T\&R Associates to develop graphite electrode DC plasma arc technology for the treatment of buried wastes. This program includes the development of advanced diagnostic systems to characterize performance, optimize operation, and control the plasma arc furnace. The DC graphite arc furnace technology has demonstrated the capability of forming a high-quality, nonleachable glass from high melting point $\left(1400-1600^{\circ} \mathrm{C}\right)$ waste and soil typical of DOE waste sites. In addition, the high-temperature region (up to $6,000^{\circ} \mathrm{C}$ ) around the DC arc can destroy organic species and vapors that evolve from the material being processed. A pilot-scale DC graphite arc furnace, Mark II, has been constructed at the MIT Plasma Fusion Center and has commenced initial operational tests. The goal of this furnace 
is to evaluate DC graphite arc technology for vitrification of wastes as part of DOE's BWID program.

PNL Report. FY-94 Summary Report Mark II DC Arc Furnace Testing. This report describes the testing of an engineering-scale $\mathrm{DC}$ arc furnace to gain preliminary operational and waste process ability information. It also includes the design, fabrication, and evaluation of a second-generation, pilot-scale graphite electrode $\mathrm{DC}$ arc furnace.

PNL Report. Safety Assessment of Mark II Furnace System. The purpose of this document is to demonstrate that the Mark II furnace system can be safely operated. This document (1) covers a complete description of the Mark II furnace system, current organizational responsibilities, and quality assurance and safety related programs, (2) incorporates analyses of hypothetical accidents, (3) assesses the margins of safety, and (4) establishes the baseline safe operating requirements for the Mark II furnace system.

PNL Report. Test Plan for FY-94 Mark II DC Arc Furnace Tests, Series II. This test plan describes the hardware and the planned testing effort for a DC Arc Graphite Electrode Furnace, which is one technology suitable for satisfying the needs of the Buried Waste Integrated Demonstration Program. 


\section{PROGRAMMATIC}

\section{TTP ID132008: BWID Program Coordination}

EGG-WTD-11136 BWID FY-93 Closeout Report. The Buried Waste Integrated Demonstration (BWID) supports the applied research, development, demonstration, and evaluation of a multitude of advanced technologies. These technologies are being integrated to form a comprehensive remediation system for the effective and efficient remediation of buried waste. These efforts are identified and coordinated in support of the DOE Environmental Restoration and Waste Management needs and objectives. BWID works with universities and private industry to develop these technologies, which are being transferred to the private sector for use nationally and internationally. A public participation policy has been established to provide stakeholders with timely and accurate information and meaningful opportunities for involvement in the technology development and demonstration process. To accomplish this mission of identifying technological solutions for remediation deficiencies, the Office of Technology Development initiated BWID at the INEL. This report summaries activities of the BWID program during FY-93.

DOE-ID-10454 BWID FY-94 Program Report. This document summarizes previous demonstrations and describes the FY-94 BWID technology development and demonstration activities. Sponsored by the DOE Office of Technology Development, BWID works with universities and private industry to develop these technologies, which are being transferred to the private sector for use nationally and internationally. A public participation policy has been established to provide stakeholders with timely and accurate information and meaningful opportunities for involvement in the technology development and demonstration process.

EGG-WTD-11123 Buried Waste Integrated Demonstration Lessons Learned 1993 Technology Demonstrations. An integrated technology demonstration was conducted by the Buried Waste Integrated Demonstration (BWID). This program and demonstration was sponsored by the U.S. Department of Energy Office of Technology Development at the INEL cold test pit in the summer of 1993 . The demonstration included six technologies representing a synergistic system for the characterization and retrieval of a buried hazardous waste site. The integrated technology demonstration proved very successful, and a summary of the technical accomplishments is presented. Members of program management and the technology deployment teams determined that additional information gained through a lessons-learned activity would enhance program planning and strengthen future technology demonstrations. Upon completion of the integrated technology demonstration, cognizant program personnel participated in a lessons-learned exercise conducted at the Simplot Decision Support Center at Idaho State University. This report discusses those lessons learned and the recommended solutions for future technical and managerial application. 


\section{TTP ID132015: BWD Technical Academic Review Group}

EGG-WTD-11422 Analysis of Automatic Guided Vehicle Technologies for Use in Buried Waste Remediation. This report analyzes the current state of the art of automatic guided vehicles (AGVs) to determine if this technology is applicable to Buried Waste Integrated Demonstration (BWID) transport needs. The report describes AGV technology, reviews literature on AGVs, and lists AGV vendors.

\section{TTP ID142013: Technology Deployment}

BP669-R1193-2MA Strategy Plan (Brochure). The Buried Waste Integrated Demonstration (BWID) is identifying, evaluating, and demonstrating technologies to support cleanup activities of hazardous and radioactive waste buried at the INEL and other DOE sites. The demonstration is funded by the DOE Office of Technology Development and coordinated by the INEL Office of Waste Technology Development. This brochure is designed to inform the public of our mission and to help interested scientists, engineers, and other professionals determine whether their own projects or technologies may be candidates for use by our program. We are also interested in developing partnerships with private sector companies to enhance commercialization opportunities for technology presently under development.

EGG-WTD-11156 BWID FY-94 Deployment Plan. This document is the basic operational planning document for deployment of all BWID projects. Discussed in this document are the BWID preparations for INEL field demonstrations, INEL laboratory demonstrations, non-INEL demonstrations, and paper studies. Each technology performing tests will prepare a test plan to detail the specific procedures, objectives, and tasks of each test. Therefore, information specific to testing each technology is intentionally omitted from this document.

EGG-WTD-10104, Rev. 2 BWID Program Technology Evaluation Report Guidance. The Technology Evaluation Report Guidance provides instructions for preparing technology evaluation reports for demonstrations supported by the Buried Waste Integrated Demonstration Program. This guidance will ensure completeness in the development of the technology evaluation report. Principal investigators are responsible for developing the technology evaluation report in accordance with this guidance.

EGG-WTD-9800, Rev. 1 BWID Technology Test Plan Guidance. The Technology Test Plan Guidance provides instructions for individuals preparing test plans to demonstrate technologies supported by the Buried Waste Integrated Demonstration.

EGG-WTD-11112 FY-94 BWID Test Goals and Objectives. This document describes the test goals and objectives for technologies evaluated by the Buried Waste Integrated Demonstration (BWID) Program. After each BWID-sponsored demonstration, the collected data will be shared with the Environmental Restoration and Waste Management (ER/WM) offices throughout the DOE complex. To ensure proper and adequate data collection, BWID has worked with the ER/WM offices to establish a minimum set of objectives that are used to guide technology testing in the areas of site/waste characterization, below-grade isolation, above-grade containment, overburden characterization/removal, retrieval, treatment, and containment. 
EGG-WTD-10266 Technology Preparedness and Status Report Guidance. A Technology Preparedness and Status Report is required for each Technical Task Plan funded by the Buried Waste Integrated Demonstration. This document provides guidance for the preparation of that report. Major sections of the report will include a subset of the need for the technology, objectives of the demonstration, technology description and readiness evaluation, demonstration requirements, and preparedness checklist and action plan.

EGG-WTD-11224 BWID Project Management Plan. This document presents the plan of activities for the Buried Waste Integrated Demonstration (BWID) Program. This plan discusses the objectives, organization, roles and responsibilities, schedules, and processes for implementing and managing BWID.

Draft Field Test Plan. Field Test Plan Buried Waste Technologies (Arid Lands) FY-95. This report will be finalized and published in FY-95 under INEL-94-0227. This document is the basic operational planning document for the deployment and testing of the technologies that support the field testing in FY-95. Discussed in this document are the scope of the tests; purpose and objectives of the tests; organization and responsibilities, contingency plans; sequence of activities; sampling and data; document control; analytical methods; data reduction, validation, and verification; quality assurance; equipment and instruments; facilities and utilities; health and safety; residuals management; and regulatory management.

EGG-WTD-11216 Environmental, Safety, Health, and Quality Plan for the Buried Waste Integrated Demonstration Program. This document describes the Environment, Safety, Health, and Quality requirements for conducting BWID activities at the INEL. Topics discussed in this report, as they apply to BWID operations, include Federal, State of Idaho, and EPA regulations, Health and Safety Plans, Quality Program Plans, data quality objectives, and training and job hazard analysis. Finally, a discussion is given on CERCLA criteria and system and performance audits as they apply to the BWID program.

\section{TTP ID142022: Technology Acceptance and Oversight}

Letter Report on WGA Demo Sites \& Schedule. This letter report documents the outcome of the BWID/EPA meeting conducted between EPA BWID program personnel. The purpose of the meeting was to discuss how the BWID Program could participate in the Site Program and how technology fact sheets are issued on selected technologies. As a result of the meeting, the final FY-94 milestone for issuing technology fact sheets cannot be met. In addition, BWID funding expectations for FY-95 will limit BWID's ability to actively pursue involvement in the EPA Site Demonstration Program.

TTP ID144101: Technology Transfer

EGG-WTD-11252 Buried Waste Integrated Demonstration Commercial Action Plan, Volume 1. This report documents commercialization action plans for five technologies with near-term commercialization/implementation potential as well as provides a status of commercial and academic partners for each technology. 
EGG-WTD-11252 Buried Waste Integrated Demonstration Commercial Action Plan, Volume 2. This report documents commercialization action plans for 10 technologies and will be revised each quarter to status additional technologies. Also provided is a status of commercial and academic partners for each BWID technology. A previous document entitled BWID Commercialization Action Plans, Volume 1 has been incorporated into this document.

EGG-WTD-11191 Buried Waste Integrated Demonstration Stakeholder Involvement Model. The Buried Waste Integrated Demonstration (BWID) is a program funded by the DOE Office of Technology Development. BWID supports the applied research, development, demonstration, and evaluation of a suite of advanced technologies that together form a comprehensive remediation system for the effective and efficient remediation of buried waste. Stakeholder participation in the DOE Environmental Management decisionmaking process is critical to remediation efforts. Appropriate mechanisms for communication with the public, private sector, regulators, elected officials, and others are being aggressively pursued by BWID to permit informed participation. This document summarizes public outreach efforts during FY-93 and presents a strategy for expanded stakeholder involvement during FY-94. 
Appendix B

List of FY-94 Technology Transfer Activities (Subcontracts, CRADAs, Licenses, Patents, MOUs with Non-DOE Federal Agencies) 

Buried Waste Integrated Demonstration FY-94 Non-DOE Partnerships

\begin{tabular}{|c|c|c|c|c|c|}
\hline TTP. Title & Contractor & State & Products, Services & $\$$ & Vehicle \\
\hline \multicolumn{6}{|l|}{ Industrial } \\
\hline $\begin{array}{l}\text { RL321211, BWID Graphite } \\
\text { OC Arc Plasma }\end{array}$ & Electro Pyrolysis Inc. & PA & Furnace deve lopment and test ing & $385 K$ & Subcont/PNL \\
\hline $\begin{array}{l}\text { ID121210, Preparation of } \\
\text { Rapid TRU Monitoring } \\
\text { Laboratory for Fieid } \\
\text { Deployment }\end{array}$ & Ordela, Inc. & TN & Large-are ionization chamber & $20 \mathrm{~K}$ & $\begin{array}{l}\text { Purchase } \\
\text { order/EG\&G }\end{array}$ \\
\hline $\begin{array}{l}\text { ID121213, Field } \\
\text { Demonstration of } \\
\text { Characterization } \\
\text { Technologies }\end{array}$ & Techn iscan & UT & $\begin{array}{l}\text { Apply geophysics data to a proprietary } \\
\text { logarithm }\end{array}$ & $62 \mathrm{~K}$ & $\begin{array}{l}\text { Subcont/EG\&G } \\
\text { (carryover) }\end{array}$ \\
\hline $\begin{array}{l}\text { ID132018, Electromagnet ic } \\
\text { Imaging }\end{array}$ & A. Anderson & & Consulting and reports & $60 \mathrm{~K}$ & Subcont/EG\&G \\
\hline $\begin{array}{l}\text { I0142003, Imaging } \\
\text { Infrared Interferometer } \\
\text { for Waste Site } \\
\text { Characterization and } \\
\text { Monitoring }\end{array}$ & Physical Sciences, Inc. & MA & $\begin{array}{l}\text { Design/construction of Fabry-Perot imaging } \\
\text { interferometer system }\end{array}$ & $250 \mathrm{~K}$ & Subcont/EG\&G \\
\hline $\begin{array}{l}\text { ID142011, Gravity Fieid } \\
\text { Measurement }\end{array}$ & Micro Geophysics Corp. & & $\begin{array}{l}\text { Demonstrate and evaluate new capability in } \\
\text { measuring gravity anomalies }\end{array}$ & $11 \mathrm{~K}$ & Subcont/EG\&G \\
\hline $\begin{array}{l}\text { ID142006, Waste } \\
\text { Conveyance for Buried } \\
\text { Waste }\end{array}$ & R.A. Hanson & WA & $\begin{array}{l}\text { Deve lop and demonstrate a waste conveyance } \\
\text { system }\end{array}$ & $406 \mathrm{~K}$ & Subcont/EG\&G \\
\hline $\begin{array}{l}\text { 10142007, Innovative End } \\
\text { Effector }\end{array}$ & R. A. Hanson & WA & $\begin{array}{l}\text { Deve lop and demonstrate an integrated system } \\
\text { to reduce dust generation and remove workers } \\
\text { from dust generation area }\end{array}$ & $210 \mathrm{~K}$ & Subcont/EGBG \\
\hline $\begin{array}{l}\text { ID-142014. Innovat ive } \\
\text { Grout Demonstration }\end{array}$ & Halliburton NUS/BRISTAR & $\mathrm{FL}$ & Grouping and fracturing & $150 \mathrm{~K}$ & Subcont/EG\&G \\
\hline $\begin{array}{l}\text { ID142016, Digital } \\
\text { Radiography }\end{array}$ & $\begin{array}{l}\text { Scient if ic Measurement Systems, } \\
\text { Inc. }\end{array}$ & $T X$ & $\begin{array}{l}\text { High-speed digital radiography and computed } \\
\text { tomagraphy of waste drums }\end{array}$ & $300 \mathrm{~K}$ & Subcont/EG\&G \\
\hline ID142018, GPR Consortium & Coleman Research & co & Use of system at cold test pit & $55 \mathrm{~K}$ & Subcont/EG\&G \\
\hline
\end{tabular}


Buried Waste Integrated Demonstration FY-94 Non-DOE Partnerships

\begin{tabular}{|c|c|c|c|c|c|}
\hline TTP, Title & Contractor & State & Products, Services & $\$$ & Vehic le \\
\hline $\begin{array}{l}\text { ID142007, Innovative End } \\
\text { Effector }\end{array}$ & Colorado School of Mines & $\mathrm{CO}$ & Technical support & $50 \mathrm{~K}$ & TTP funding \\
\hline ID142018, GPR Consortium & Ohio State University & $\mathrm{OH}$ & GPR/Geophys ics Workshop & $30 \mathrm{~K}$ & Subcont/EG\&G \\
\hline $\begin{array}{l}\text { ID142016, Digital } \\
\text { Radiography }\end{array}$ & Idaho State University & ID & Test Machine & $10 \mathrm{~K}$ & Subcont/EG\&G \\
\hline $\begin{array}{l}\text { ID142015, Excavated Waste } \\
\text { Assay }\end{array}$ & Idaho State University & ID & Facilities/Provide research student & $50 \mathrm{~K}$ & Subcont/EG\&G \\
\hline $\begin{array}{l}\text { ID142020, Machine Health } \\
\text { Monitoring }\end{array}$ & Colorado School of Mines & $\mathrm{CO}$ & Operate test bench for data collection & $50 \mathrm{~K}$ & Subcont/EG\&G \\
\hline $\begin{array}{l}\text { AL142002, off-Gas } \\
\text { Treatment }\end{array}$ & University of Illinois & IL & $\begin{array}{l}\text { Demonstration of technology aimed at air } \\
\text { toxics }\end{array}$ & $50 \mathrm{~K}$ & Subcont/EG\&G \\
\hline $\begin{array}{l}\text { SF221209, NDA } \\
\text { Characterization for } \\
\text { TRU/LLW }\end{array}$ & $\begin{array}{l}\text { University of California at San } \\
\text { Francisco }\end{array}$ & $\mathrm{CA}$ & Provide equipment and software & $100 \mathrm{~K}$ & Subcont/EG\&G \\
\hline $\begin{array}{l}\text { ID132022, } 30 \text { Dynamic } \\
\text { Graphic Simulation of } \\
\text { Retrieval Configuration } \\
\text { Options }\end{array}$ & Colorado School of Mines & $\mathrm{CO}$ & $\begin{array}{l}\text { Provide a graphical 3-D Dynamic Simulation } \\
\text { Tool }\end{array}$ & $64 K$ & Subcont/EG\&G \\
\hline \multicolumn{6}{|l|}{ 0ther Federal Agencies } \\
\hline $\begin{array}{l}\text { ID121112, Nonintrusive } \\
\text { Site Characterization }\end{array}$ & U.S. Geological Survey & $\mathrm{CO}$ & $\begin{array}{l}\text { Evaluation of magnetic and electromagnetic } \\
\text { data sets }\end{array}$ & $10 K$ & $\begin{array}{l}\text { Inter-agency } \\
\text { fund transfer }\end{array}$ \\
\hline $\begin{array}{l}\text { AL911201, Nonintrusive } \\
\text { Sensing of } \\
\text { Environmentally Important } \\
\text { Objects and Species, } \\
\text { Tensor Magnet ic } \\
\text { Gradiometer }\end{array}$ & U.S. Geological Survey & $\mathrm{CO}$ & $\begin{array}{l}\text { Design and fabricate sensor, develop } \\
\text { acquisition and reduction software, and } \\
\text { modify TMG system for mobile application }\end{array}$ & $163 \mathrm{~K}$ & $\begin{array}{l}\text { Inter-agency } \\
\text { fund transfer }\end{array}$ \\
\hline $\begin{array}{l}\text { ID132003, BWID Dig-face } \\
\text { Characterization }\end{array}$ & U.S. Geological Survey & $\mathrm{CO}$ & Trench data interpretation & $70 \mathrm{~K}$ & $\begin{array}{l}\text { Inter-agency } \\
\text { fund transfer }\end{array}$ \\
\hline $\begin{array}{l}\text { ID132011, Arc Melter } \\
\text { Vitrification }\end{array}$ & U.S. Bureau of Mines & OR & Furnace testing & $750 \mathrm{~K}$ & $\begin{array}{l}\text { MPO/DOE-ID to } \\
\text { USBM }\end{array}$ \\
\hline
\end{tabular}

